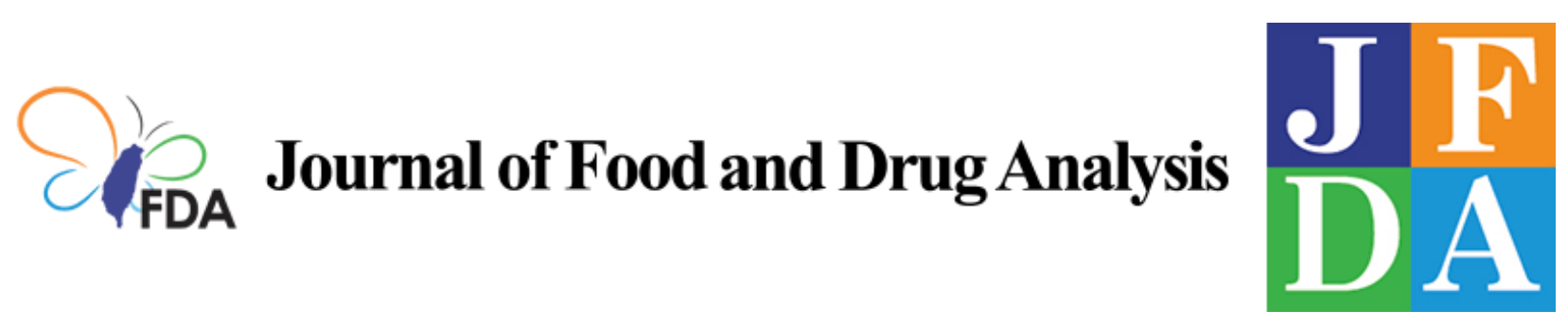

Volume 28 | Issue 2

Article 13

2020

\title{
Evaluation of Analysis of Cholesterol Oxidation Products and Heterocyclic Amines in Duck and Their Formation as Affected by Roasting Methods
}

Follow this and additional works at: https://www.jfda-online.com/journal

Part of the Food Science Commons, Medicinal Chemistry and Pharmaceutics Commons, Pharmacology Commons, and the Toxicology Commons

(c) (i) (9)

This work is licensed under a Creative Commons Attribution-Noncommercial-No Derivative Works 4.0 License.

\section{Recommended Citation}

Hsu, Kai-Yu; Inbaraj, Baskaran Stephen; and Chen, Bing-Huei (2020) "Evaluation of Analysis of Cholesterol Oxidation Products and Heterocyclic Amines in Duck and Their Formation as Affected by Roasting Methods," Journal of Food and Drug Analysis: Vol. 28 : Iss. 2 , Article 13.

Available at: https://doi.org/10.38212/2224-6614.1066

This Original Article is brought to you for free and open access by Journal of Food and Drug Analysis. It has been accepted for inclusion in Journal of Food and Drug Analysis by an authorized editor of Journal of Food and Drug Analysis. 


\title{
Evaluation of analysis of cholesterol oxidation products and heterocyclic amines in duck and their formation as affected by roasting methods
}

\author{
Kai-Yu Hsu ${ }^{a, 1}$, Baskaran Stephen Inbaraj ${ }^{a, 1}$, Bing-Huei Chen ${ }^{a, b, *}$ \\ ${ }^{a}$ Department of Food Science, Fu Jen Catholic University, New Taipei City 242, Taiwan \\ ${ }^{\mathrm{b}}$ Department of Nutrition, China Medical University, Taichung 404, Taiwan
}

\begin{abstract}
Roast duck, a popular meat commodity in Asian countries especially Taiwan and China, can produce many types of toxic compounds such as cholesterol oxidation products (COPs) and heterocyclic amines (HAs). The objectives of this study were to evaluate analysis of COPs and HAs in duck by GC-MS and UPLC-MS/MS respectively, and study their formation as affected by roasting methods including traditional oven, fan oven and superheated steam oven. Results showed that both high precision and accuracy was attained by using the QuEChERS method with reduced separation time of $14 \mathrm{~min}$ for 7 COPs and $4.5 \mathrm{~min}$ for 21 HAs by GC-MS and UPLC-MS/MS, respectively. The duck meat roasted in both superheated steam oven and traditional oven generated significantly higher levels of total COPs than fan oven, while for total HAs, both traditional oven and fan oven produced significantly higher levels than superheated steam oven. Compared to roast duck skin, a much higher level of total COPs was shown in roast duck meat, while a reversed tendency was shown for total HAs. Furthermore, the correlation between formation of COPs and HAs in roast duck skin showed no significant correlation $(p>0.05)$ for traditional oven, fan oven and superheated steam oven, while in roast duck meat, only traditional oven showed significant correlation $(\mathrm{p}<0.05)$. However, by taking both duck skin and meat into account, superheated steam oven produced the lowest level of total HAs, while fan oven generated the lowest level of total COPs. Thus, the developed method can form a basis for determination of COPs and HAs in duck as well as by choosing an appropriate roasting method their formation can be minimized.
\end{abstract}

Keywords: Cholesterol oxidation products (COPs), Heterocyclic amines (HAs), Roast duck, QuEChERS, UPLC-MS/MS, GC-MS

\section{Introduction}

B oth cholesterol oxidation products (COPs) and heterocyclic amines (HAs) represent an important class of toxic compounds in processed meat products, with the former mainly present in cholesterol-rich foods and the latter in proteinrich foods [1,2]. Of the various meat products, ham, bacon and sausage are classified as the group 1-level carcinogens (carcinogenic to humans) and red meat classified as the group-2Alevel carcinogens (probably carcinogenic to humans), based on a report by the International
Agency for Research on Cancer [3] in 2015. Since then the safety associated with consumption of meat products has become a vital issue to debate worldwide.

The formation and inhibition of COPs and HAs in meat products as affected by various processing methods have been well documented $[4,5]$. However, due to their presence in trace amount (ppm or $\mathrm{ppb}$ ) and the complexity of meat matrix, the analysis of COPs and HAs in meat products has been difficult. In the literature reports COPs are often analyzed by solvent extraction, followed by purification with solid phase extraction, identification and quantitation by gas chromatography-mass

1 Equally contributed to this article. 
spectrometry (GC-MS). Similarly, HAs are often extracted and purified using solid-phase extraction, followed by high performance liquid chromatography-mass spectrometry (HPLC-MS) or HPLCtandem MS (HPLC-MS/MS) for identification and quantitation. However, both extraction and purification methods as well as separation are lengthy $[4,6]$. To further shorten the extraction time, several authors used QuEChERS (quick, easy, cheap, effective, rugged, safe) method for extraction and purification of COPs or HAs from meat products [2,5].

Accordingly, HAs can be divided into thermic HAs and pyrolytic HAs, with the former being produced through reaction among sugar, amino acid and creatine with temperature at $100-300{ }^{\circ} \mathrm{C}$, and the latter generated through degradation of protein or amino acid with temperature at $>300{ }^{\circ} \mathrm{C}$ [7]. More specifically, for thermic HAs, the compound $\alpha, \beta$-dicarbonyl can be formed initially through reaction between 6-carbon sugar and amino acid, followed by formation of $\alpha$-aminocarbonyl compound through Strecker degradation, formation of pyridine or pyrazine through cyclization, formation of imidazole through reaction between aldehyde compound from Strecker degradation and creatine, leading to formation of imidazoquinoline (IQ type HAs) and imidazoquinoxaline (IQx type HAs) [8]. However, for pyrolytic HAs, both Trp-P-1 and Trp-P-2 can be formed through pyrolysis of tryptophan, while Glu-P-1 and Glu-P-2 formed from glutamic acid as well as $\mathrm{A} \alpha \mathrm{C}$ and $\mathrm{MeA} \alpha \mathrm{C}$ from soybean globulin [9].

Many factors including cooking method, temperature, time, food variety, food composition, flavoring and antioxidant addition, and water activity have been demonstrated to affect the type and amount of HAs formed in processed food products. For instance, Gibis et al. [10] studied the formation and inhibition of HAs in fried bacon and reported a much higher level of HAs with cooking temperature at $200-220{ }^{\circ} \mathrm{C}$ than at $150-170{ }^{\circ} \mathrm{C}$. Also, the HA levels followed a time-dependent increase. Similarly, both temperature- and time-dependent rise in HA levels was observed in fried ground beef patties following cooking at 175,200 and $225^{\circ} \mathrm{C}$ for 12 or $20 \mathrm{~min}$ [11]. In addition, the incorporation of antioxidants such as vitamin $C$ and conjugated linoleic acid were shown to be effective in inhibiting HAs formation in beef patties and meatballs by Wong et al. [12] and $\mathrm{Oz}$ et al. [13], respectively. Like HAs, the formation of COPs also followed a time- and temperature-dependent increase during heating of cholesterol [14]. In meat products, several COPs such as $7 \alpha$-hydroxy cholesterol $(7 \alpha-\mathrm{OH}), 7 \beta$-hydroxy

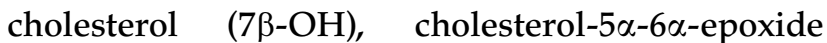
(5,6 $\alpha$-EP), cholesterol- $5 \beta-6 \beta$-epoxide $(5,6 \beta$-EP), $5 \alpha$ cholestane-3 $\beta-5 \alpha$-triol (triol), 25 -hydroxy cholesterol $(25-\mathrm{OH})$ and 7 -keto cholesterol (7-keto) were detected during heating [4]. Of various cooking methods, microwave cooking and baking were shown to produce a higher level of COPs in sausage and ham [15], while lipid oxidation proceeded faster in foal meat [16]. Also, the incorporation of antioxidants such as vitamin $E$ and apple polyphenol were effective in inhibiting COPs formation in meat products during heating $[17,18]$.

The mechanism of cholesterol oxidation has been demonstrated to be similar to lipid oxidation [19]. During initial oxidation, $7 \alpha$-hydroperoxy cholesterol $(7 \alpha-\mathrm{OOH})$ or $7 \beta$-hydroperoxy cholesterol $(7 \beta-\mathrm{OOH})$ can be formed through formation of a free radical at 7th carbon of cholesterol and reaction with oxygen and a hydrogen atom, followed by reduction for formation of $7 \alpha-\mathrm{OH}$ or $7 \beta-\mathrm{OH}$ or dehydration for 7 keto formation. Alternatively, in the presence of $7 \alpha-$ $\mathrm{OOH}$ or $7 \beta-\mathrm{OOH}, 5,6 \alpha-\mathrm{EP}$ or $5,6 \beta$-EP can be formed from cholesterol, followed by triol formation under aqueous and acidic condition [19]. Also, two side chain oxidation products such as 20-hydroxy cholesterol $(20-\mathrm{OH})$ or $25-\mathrm{OH}$ can be formed directly from cholesterol [19]. The association between intake of COPs in excess and incidence of atherosclerosis has been reported [20,21].

Roast duck, often processed by traditional oven with gas heater as a heat source, is a popular meat commodity in Taiwan and China. As both HAs and COPs can be generated in high amount by the traditional oven method, the effects of some other roasting methods such as fan oven and superheated steam oven on formation of COPs and HAs in roast duck remain unexplored. Meanwhile the analysis of HAs and COPs in roast duck by QuEChERS method coupled with UPLC-MS/MS and GC-MS, respectively, will be evaluated for accuracy and precision.

\section{Materials and methods}

\subsection{Materials}

A total of 9 raw whole duck with an approximate weight of $2.5 \mathrm{~kg}$ each were procured from a local market in Taipei, Taiwan. Also, a total of 10 whole roast duck were purchased from 5 roast duck shops located in east, west, central, north, south regions of Taipei, Taiwan, with 2 each.

Standards including cholesterol, $5 \alpha$-cholestane (internal standard), 5,6 $\alpha$-EP, 5,6 $\beta$-EP, 7-keto, 25-OH, and triol were from Sigma-Aldrich Co (St. Louis, MO, USA). Both $7 \alpha-\mathrm{OH}$ and $7 \beta-\mathrm{OH}$ standards were 
from Steraloids Co (Wilton, NH, USA). A total of 21 HA standards, including 9H-pyrido[3,4- $b]$ indole (norharman), 1-methyl-9H-pyrido[3,4-b]indole (harman), 3-amino-1,4-dimethyl-5H-pyrido[4,3-b] indole (Trp-P-1), 3-amino-1-methyl-5H-pyrido[4,3$b$ ]indole (Trp-P-2), 2-amino-9H-pyrido[2,3-b]indole $(\mathrm{A} \alpha \mathrm{C}), \quad 2$-amino-3-methyl-9H-pyrido[2,3-b]indole $(\mathrm{MeA} \alpha \mathrm{C})$, (2-amino-1-methyl-6-phenylimidazo[4,5b]-pyridine (PhIP), 2-amino-5-phenylpyridine (PheP-1), 2-amino-1,6-dimethyl-furo[3,2-e]imidazo[4,5b]-pyridine (IFP), 2-amino-3,8-dimethyl-imidazo [4,5-f]-quinoxaline (8-MeIQx), 2-amino-3,7,8-trimethyl-imidazo[4,5-f]-quinoxaline (7,8-DiMeIQx), 2-amino-3,4,8-trimethyl-imidazo[4,5-f]-quinoxaline (4,8-DiMeIQx), 2-amino-6-methyldipyrido-[1,2a:3', $2^{\prime}$-d] imidazole (Glu-P-1), 2-aminodipyrido-[1,2$a: 3^{\prime}, 2^{\prime}$-d] imidazole (Glu-P-2), 2-amino-1,6-dimethylimidazo[4,5- $b]$-pyridine (DMIP), 2-amino-3methyl-imidazo[4,5-f]-quinoline (IQ), 2-amino-1methyl-imidazo[4,5-f]-quinoline (iso-IQ), 2-amino3-methyl-imidazo[4,5-f]-quinoxaline (IQx), 2amino-3,4-dimethyl-imidazo[4,5-f]-quinoline

(MeIQ), 2-amino-3-methyl-imidazo[4,5-b]-quinoline (IQ [4,5-b]) and internal standard 2-amino-3,4,7,8tetramethyl-imidazo[4,5-fl-quinoxaline $\quad(4,7,8$-TriMeIQx) were from Toronto Research Chemical Co (Downsview, Ontario, Canada). An ACQUITY UPLC BEH C18 column $(50 \mathrm{~mm} \times 2.1 \mathrm{~mm}$ ID, particle size $1.7 \mu \mathrm{m}$ ) used to separate $21 \mathrm{HAs}$ was from Waters Co (Milford, MA, USA), while a DB-5MS capillary column $(30 \mathrm{~m} \times 0.25 \mathrm{~mm}$ ID, film thickness $0.25 \mu \mathrm{m}$ ) used to separate cholesterol, $5 \alpha$-cholestane and 7 COPs was from Agilent Technologies (Palo Alto, CA, USA).

The analytical grade solvent acetone and HPLC grade solvents methanol and acetonitrile were from Merck (Darmstadt, Germany). Pyridine was from J.T. Baker Co (Phillipsburg, NJ, USA). Glacial acetic acid was from Sigma-Aldrich Co. Deionized water was made using a Milli-Q water purification system (Millipore Co, Bedford, MA, USA). The QuEChERS extraction kit containing extraction powder (product no. UR-EX) and purification powder (product no. UR-CLEAN-II) was from Yu-Ho Trade Co (New Taipei City, Taiwan). The Sylon BTZ containing N,O-Bis(trimethylsilyl)acetamide (BSA):Trimethylchlorosilane (TMCS):Trimethylsilylimidazole (TMSI) (3:2:3) was from Supelco Co (Bellefonte, PA, USA).

\subsection{Separation and identification of HAs by UPLC- MS/MS and COPs by GC-MS}

The modified UPLC mobile phase used to separate 21 HAs contained (A) $30 \mathrm{mM}$ ammonium acetate buffer solution ( $\mathrm{pH} 4.75)$ and (B) acetonitrile with column temperature at $25{ }^{\circ} \mathrm{C}$, flow rate at $0.7 \mathrm{~mL} / \mathrm{min}$ and the following gradient elution: $95 \%$ $\mathrm{A}$ and 5\% B initially, maintained for $2 \mathrm{~min}$, increased to $90 \% \mathrm{~B}$ in $3.3 \mathrm{~min}$, decreased to $5 \% \mathrm{~B}$ in $4.1 \mathrm{~min}$, and maintained till $4.5 \mathrm{~min}$ before next injection. The various HAs in duck samples were detected by selected reaction monitoring (SRM) mode by a Dionex Ultimate 3000 model Open Sampler XRS UPLC system coupled with TSQ Quantiva triple quadrupole tandem mass spectrometer with electrospray ionization from Thermo Fisher Scientific Co. (San Jose, CA, USA), with vaporizer temperature at $279{ }^{\circ} \mathrm{C}$, ion transfer tube temperature at $329{ }^{\circ} \mathrm{C}$, spray voltage at $2700 \mathrm{~V}$, sweep gas flow rate at 2 arbitrary units, collision gas flow rate at 1.5 arbitrary units, auxiliary gas flow rate at 9 arbitrary units and sheath gas flow rate at 4 arbitrary units. Table 1 shows the operation parameters such as precursor ion as well as quantitation ion and confirmation ion along with their corresponding collision energy used for differentiating each HA. Although the isomers 7,8-DiMeIQx and 4,8-DiMeIQx possess the same precursor and confirmation ions, they are differentiated based on their quantitation ions (mass-to-charge ratio $\mathrm{m} / \mathrm{z}$ 131.13 and 213.09). For cholesterol, $5 \alpha$-cholestane and 7 COPs, a 6890 model Agilent GC instrument coupled with 5973 model mass spectrometer (Agilent Technologies, Palo Alto, CA, USA) and G4513A model autosampler was used with the separation condition based on a previous report by Chiu et al. [2]. Also, a DB-5MS capillary column $(30 \mathrm{~m} \times 0.25 \mathrm{~mm}$ ID, film thickness $0.25 \mu \mathrm{m})$ from Agilent was used with $\mathrm{He}$ at flow rate $1 \mathrm{~mL} / \mathrm{min}$, splitless mode, injector temperature $280{ }^{\circ} \mathrm{C}$, MS interface temperature $300{ }^{\circ} \mathrm{C}$, and the following temperature programming condition: $250{ }^{\circ} \mathrm{C}$ in the beginning, raised to $290^{\circ} \mathrm{C}$ at $10^{\circ} \mathrm{C} / \mathrm{min}$, maintained for $5 \mathrm{~min}$, raised to $291{ }^{\circ} \mathrm{C}$ at $0.1{ }^{\circ} \mathrm{C} / \mathrm{min}$ and maintained for $1 \mathrm{~min}$. A complete separation was attained within $14 \mathrm{~min}$. Also, a selected ion monitoring (SIM) mode was used to detect various COPs in duck samples according to elution order and specific $\mathrm{m} / \mathrm{z}$ as described in a previous study [2].

\subsection{Processing of roast duck}

Initially the inedible parts of each duck including wing and web were removed and washed (step 1), followed by spraying with $125 \mathrm{~g}$ maltose solution $(5 \%)$ (step 2), hanging and air drying for $1 \mathrm{~h}$ (step 3 ), and then roasting at $250{ }^{\circ} \mathrm{C}$ for $40 \mathrm{~min}$ (step 4) (Fig. 1A). Also, the appearance of duck roasted in traditional oven (medium brownish), hot oven (dark 
brownish) and superheated steam oven (dark yellow to brownish) at $250{ }^{\circ} \mathrm{C}$ for $40 \mathrm{~min}$ are shown in Fig. 1B. The roasting condition of $250^{\circ} \mathrm{C}$ for $40 \mathrm{~min}$ was chosen by optimizing temperature and time sufficient to cause complete roasting of duck. Triplicate experiments were carried out and a total of 9 raw whole ducks were used in this study with 3 ducks for each treatment roasted in 3 separate ovens. After roasting the whole duck, the skin and meat portions were carefully separated by hand followed by slowly pulling out the bones from the meat. Prior to QuEChERS extraction, the roast duck skin or meat samples were thoroughly homogenized by grinding into a paste.

\subsection{Extraction and purification of HAs and COPs in raw, boiled and roast duck}

The extraction and purification of HAs or COPs in raw, boiled and roast duck was based on two previous studies [1,2]. In brief, for HAs extraction and purification, a 2-g homogenized duck sample was poured into a $50-\mathrm{mL}$ centrifuge tube and one ceramic homogenizer was added. Then $10-\mathrm{mL}$ deionized water was added, shaken for $10 \mathrm{~min}$ (200 rpm), added with $10 \mathrm{~mL}$ acetonitrile containing $1 \%$ acetic acid, and shaken again for $10 \mathrm{~min}$ $(200 \mathrm{rpm})$. Next, the extraction powder containing anhydrous magnesium sulfate $(4 \mathrm{~g})$ and anhydrous sodium acetate $(1 \mathrm{~g})$ was added, followed by shaking vigorously for $1 \mathrm{~min}$, centrifuging at $3200 \mathrm{~g}$ for $10 \mathrm{~min}\left(4^{\circ} \mathrm{C}\right)$, collecting the supernatant $(6 \mathrm{~mL})$, and pouring into a centrifuge tube containing anhydrous magnesium sulfate $(900 \mathrm{mg})$, PSA $(300 \mathrm{mg})$ and C18EC (300 mg). After shaking for $1 \mathrm{~min}$ and centrifuging at $3200 \mathrm{~g}$ for $5 \mathrm{~min}\left(4^{\circ} \mathrm{C}\right)$, the supernatant $(1 \mathrm{~mL})$ was collected, evaporated to dryness under nitrogen, dissolved in $0.2 \mathrm{~mL}$ methanol containing the internal standard 4,7,8-TriMeIQx (1 $\mathrm{ppb}$ ), and filtered through a $0.22-\mu \mathrm{m}$ poly(vinylidene fluoride) (PVDF) membrane filter for injection into UPLC-MS/MS.

Similarly, for extraction and purification of COPs, a QuEChERS method as described above was used with the exception that acetone was used instead of acetonitrile. This is because acetone provided much higher recovery of COPs compared to acetonitrile. A GC-MS chromatogram showing higher peak responses for different COPs extracted using acetone as solvent in comparison with acetonitrile was published elsewhere [2]. Also, after evaporating to dryness under nitrogen, the residue was dissolved in pyridine containing the internal standard $5 \alpha$ cholestane $(2 \mathrm{ppm})$, followed by adding $40 \mu \mathrm{L}$ of Sylon BTZ for derivatization in the dark for $1 \mathrm{~h}$ and filtering through a $0.22-\mu \mathrm{m}$ Nylon membrane filter for GC-MS analysis.

Table 1. Retention time and operation parameters of 20 HAs and one internal standard (IS) in selected reaction monitoring (SRM) mode by UPLCMS/MS.

\begin{tabular}{|c|c|c|c|c|c|c|c|}
\hline \multirow{2}{*}{$\begin{array}{l}\text { Peak } \\
\text { No. }\end{array}$} & \multirow[t]{2}{*}{ Compound } & \multirow[t]{2}{*}{ Retention time ( $\mathrm{min}$ ) } & \multirow{2}{*}{$\begin{array}{l}\text { Precursor } \\
\text { ion }(\mathrm{m} / \mathrm{z})\end{array}$} & \multicolumn{2}{|l|}{ Quantitation } & \multicolumn{2}{|l|}{ Confirmation } \\
\hline & & & & Product ion $(\mathrm{m} / \mathrm{z})$ & $\begin{array}{l}\text { Collision } \\
\text { energy (V) }\end{array}$ & Product ion $(m / z)$ & $\begin{array}{l}\text { Collision } \\
\text { energy (V) }\end{array}$ \\
\hline 1 & DMIP & 0.74 & 163.10 & 148.10 & 24 & 105.09 & 37 \\
\hline 2 & Glu-P-2 & 1.22 & 185.10 & 158.10 & 25 & 78.05 & 37 \\
\hline 3 & iso-IQ & 1.25 & 199.09 & 184.12 & 25 & 158.14 & 21 \\
\hline 4 & IQ & 1.65 & 199.10 & 184.12 & 27 & 131.09 & 29 \\
\hline 5 & IQx & 1.67 & 200.08 & 185.12 & 28 & 132.14 & 29 \\
\hline 6 & 8-MeIQx & 2.65 & 214.10 & 131.07 & 41 & 173.18 & 24 \\
\hline 7 & Glu-P-1 & 2.72 & 199.10 & 92.10 & 36 & 172.14 & 26 \\
\hline 8 & MeIQ & 2.74 & 213.11 & 198.09 & 27 & 145.15 & 29 \\
\hline 9 & $\mathrm{IQ}[4,5-\mathrm{b}]$ & 2.78 & 199.11 & 183.92 & 27 & 115.19 & 46 \\
\hline 10 & IFP & 2.80 & 203.08 & 188.17 & 25 & 175.14 & 22 \\
\hline 11 & 7,8-DiMeIQx ${ }^{a}$ & 2.82 & 228.10 & 131.13 & 40 & 187.15 & 25 \\
\hline 12 & 4,8-DiMeIQx ${ }^{a}$ & 2.84 & 228.10 & 213.09 & 26 & 187.09 & 23 \\
\hline 13 & Norharman & 2.92 & 169.06 & 115.09 & 33 & 89.05 & 48 \\
\hline IS & 4,7,8-TriMeIQx & 2.93 & 242.13 & 145.09 & 42 & 201.21 & 26 \\
\hline 14 & Harman & 2.94 & 183.09 & 115.15 & 34 & 89.09 & 49 \\
\hline 15 & Trp-P-2 & 2.97 & 198.11 & 154.14 & 30 & 181.08 & 24 \\
\hline 16 & Trp-P-1 & 3.01 & 212.12 & 195.14 & 24 & 168.09 & 30 \\
\hline 17 & Phe-P-1 & 3.04 & 171.09 & 127.13 & 30 & 154.07 & 21 \\
\hline 18 & PhIP & 3.07 & 225.10 & 210.05 & 30 & 140.08 & 54 \\
\hline 19 & $\mathrm{~A} \alpha \mathrm{C}$ & 3.20 & 184.07 & 140.13 & 33 & 167.07 & 24 \\
\hline 20 & $\mathrm{MeA} \alpha \mathrm{C}$ & 3.29 & 198.10 & 181.14 & 23 & 127.13 & 38 \\
\hline
\end{tabular}

${ }^{a}$ Although the isomers 7,8-DiMeIQx and 4,8-DiMeIQx possess the same precursor and confirmation ions, they are differentiated based on their quantitation ions $(m / z 131.13$ and 213.09). 


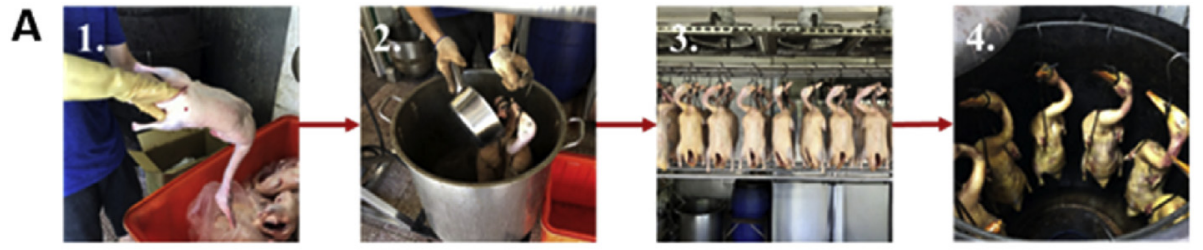

B

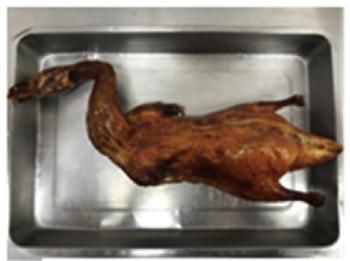

Traditional oven

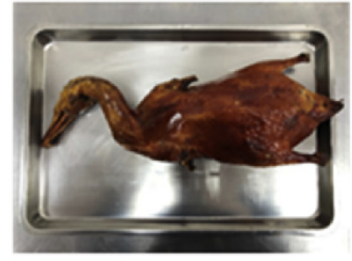

Fan oven

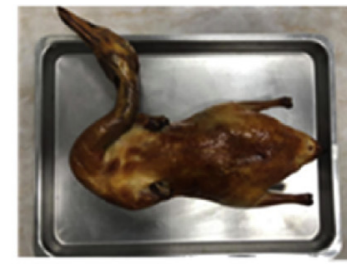

Superheated steam oven

Fig. 1. Panels showing the flow chart of different steps involved in roast duck process (A) such as removing the inedible parts and washing (step 1), spraying with 5\% hot maltose solution (step 2), hanging and air drying for $1 \mathrm{~h}$ (step 3) and roasting at $250{ }^{\circ} \mathrm{C}$ for $40 \mathrm{~min}$ (step 4) as well as the appearance of roast duck processed by different methods (B).

\subsection{Matrix effect evaluation}

A method based on Chang et al. [22] was used for determination of matrix effect of COPs and HAs in boiled duck skin and meat. A total of 5 concentrations $(0.4,1.2,2,4,10 \mu \mathrm{g} / \mathrm{mL})$ of 7 COP standard solutions dissolved in pyridine were prepared separately, after which $40 \mu \mathrm{L}$ was collected and poured into a vial containing $250-\mu \mathrm{L}$ inner tube, followed by adding $5 \alpha$-cholestane $(2 \mu \mathrm{g} / \mathrm{mL})$, derivatizing and injecting each concentration into GC-MS for preparation of standard calibration curves (SCC) by plotting concentration ratio against area ratio to obtain linear regression equations. The linear regression equations (coefficient of determination, $\left.\mathrm{r}^{2}\right)$ were $\mathrm{y}=2.8693 \mathrm{x}-1.6287 \quad(0.9951)$, $\mathrm{y}=4.3679 \mathrm{x}-2.8002(0.9954), \mathrm{y}=0.1179 \mathrm{x}-0.0844$ (0.9923), $\mathrm{y}=0.1311 \mathrm{x}-0.0917(0.9927), \mathrm{y}=0.7275 \mathrm{x}-$ $0.4654(0.9962), y=1.0723 x-0.7881 \quad(0.9981)$ and $\mathrm{y}=0.2078 \mathrm{x}-0.1249(0.9942)$ for $7 \alpha-\mathrm{OH}, 7 \beta-\mathrm{OH}, 5,6 \beta-$ $\mathrm{EP}, 5,6 \alpha-\mathrm{EP}$, triol, $25-\mathrm{OH}$ and 7 -keto, respectively. Likewise, a total of 5 concentrations $(0.05,0.1,0.5,1$, $2 \mathrm{ng} / \mathrm{mL}$ ) of 20 HA standards dissolved in methanol containing 4,7,8-TriMeIQx at $1 \mathrm{ng} / \mathrm{mL}$ were prepared separately and injected into UPLC-MS/MS for preparation of SCC. The linear regression equations (coefficient of determination, $\mathrm{r}^{2}$ ) were $\mathrm{y}=28.9311 \mathrm{x}+0.4343(0.9973), \mathrm{y}=9.0299 \mathrm{x}+$ $0.6458 \quad(0.9996), \quad \mathrm{y}=32.2483 \mathrm{x}-5.7816 \quad(0.9999)$, $\mathrm{y}=33.3046 \mathrm{x}-7.6808(0.9974), \mathrm{y}=11.8278 \mathrm{x}+0.3097$ $(0.9958), y=7.2860 \mathrm{x}+0.2879 \quad(0.9939)$, $\mathrm{y}=9.0299 \mathrm{x}+0.6458(0.9945), \mathrm{y}=28.9311 \mathrm{x}+0.4343$ $(0.9970), \quad \mathrm{y}=13.5228 \mathrm{x}+0.3004 \quad(0.9970), \mathrm{y}=$ $22.5630 \mathrm{x}+1.2957 \quad(0.9960), \quad \mathrm{y}=10.0157 \mathrm{x}+1.9738$ (0.9991), $\mathrm{y}=22.147 \mathrm{x}+1.8230(0.9995), \mathrm{y}=58.8894 \mathrm{x}+$ $2.4937(0.9989), \quad \mathrm{y}=86.4574 \mathrm{x}+4.2991 \quad(0.9996)$, $\mathrm{y}=18.2925 \mathrm{x}-0.2005(0.9995), \mathrm{y}=39.0165 \mathrm{x}+2.7680$ (0.9992), $\mathrm{y}=31.4564 \mathrm{x}+10.7756(0.9999), \mathrm{y}=19.9237 \mathrm{x}-$ $0.8899(0.9997), y=8.2538 x-1.2328(0.9982)$ and $\mathrm{y}=14.8182 \mathrm{x}-0.9620$ (0.9993), for DMIP, Glu-P-2, IsoIQ, IQ, IQx, 8-MeIQx, Glu-P-1, MeIQ, IQ [4,5-b], IFP, 7,8-DiMeIQx, 4,8-DiMeIQx, norharman, harman, Trp-P-2, Trp-P-1, Phe-P-1, PhIP, A $\alpha \mathrm{C}$ and $\mathrm{MeA} \alpha \mathrm{C}$, respectively.

For preparation of matrix-matched calibration curves (MCC), the same 5 concentrations $(0.4,1.2,2$, $4,10 \mu \mathrm{g} / \mathrm{mL}$ ) of COP standard solutions containing $5 \alpha$-cholestane were also prepared, added to boiled duck breast extract (skin and meat) for extraction, purification and derivatization using the same procedures shown above prior to injection into GC-MS. Similarly, the MCC for HAs were obtained by preparing the same 5 concentrations $(0.05,0.1$, $0.5,1,2 \mathrm{ng} / \mathrm{mL}$ ) of $20 \mathrm{HA}$ standards containing $4,7,8-$ TriMeIQx and adding to boiled duck breast extract (skin and meat) for extraction and purification prior to injection into UPLC-MS/MS. However, we have to point out here that the matrix effects of harman, norharman and Trp-P-1 were not determined as they were present in small amounts in boiled duck breast skin and meat. The matrix effects of both COPs and HAs were calculated using a formula as shown below [22]:

Matrix effects $(\%)=\frac{\text { slope of } \mathrm{MCC}-\text { slope of SCC }}{\text { slope of SCC }} \times 100$

\subsection{Method validation}

Both limit of detection (LOD) and limit of quantitation (LOQ) of COPs and HAs were determined 
using the same approach as described in several previous studies [1,2]. Briefly, a total of 15 concentrations $(0.01-1.0 \mu \mathrm{g} / \mathrm{mL})$ and 7 concentrations $(0.005-0.1 \mathrm{ng} / \mathrm{mL})$ were prepared for each COP and HA standard, respectively. After injection into GC-MS and HPLC-MS/MS, the LOD of COPs were based on $S / N \geq 3$ of peaks for the former and $S /$ $\mathrm{N} \geq 3$ of quantitative ion peaks for the latter. For LOQ, the COPs were based on peaks $S / N \geq 10$ following injection into GC-MS, while the HAs were based on $S / N \geq 10$ of quantitative ion peak and $S / N \geq 3$ of qualitative ion peak following addition of HA standards to blank samples (boiled duck breast skin and meat), extraction, purification and injection into UPLC-MS/MS.

For the precision study, the COP standard solutions $(1 \mu \mathrm{g} / \mathrm{g}$ each) were added to a tube containing blank sample (boiled duck skin or meat) for extraction, purification, derivatization and injection into GC-MS in the morning, afternoon and evening on the same day for the intra-day variability determination. Likewise, the intra-day variability of HAs was determined using the same approach as COPs with the exception that the HA concentration in blank samples was controlled at $1 \mathrm{ng} / \mathrm{g}$, and without derivatization prior to injection into UPLC-MS/MS. Triplicate analyses were conducted and the standard deviation (SD) and coefficient of variation (CV) for both COPs and HAs were calculated. Similarly, the inter-day variability was performed as the intraday variability with the exception that the analysis was carried out on the 1st, 2nd and 3rd day in triplicate each day.

For the accuracy study, two concentrations of COPs ( 1 and $5 \mu \mathrm{g} / \mathrm{g}$ ) were added to a tube containing blank sample (boiled duck skin or meat) for extraction, purification, derivatization, injection into GC-MS and quantitation for COPs. But for HAs, the same approach was used with the exception that two concentrations ( 1 and $10 \mathrm{ng} / \mathrm{g}$ ) were used and without derivatization prior to injection into UPLCMS/MS for quantitation. Then the recovery of each COP or HA was calculated based on a formula described in several previous studies $[1,2]$.

\subsection{Quantitation of COPs and HAs}

For preparation of the standard curves of both COPs and HAs, 5 concentrations $(0.4,1.2,2,4,10 \mu \mathrm{g} /$ $\mathrm{mL}$ ) of 7 COP standards in pyridine containing $5 \alpha-$ cholestane at $2 \mu \mathrm{g} / \mathrm{mL}$ and 5 concentrations $(0.05$, $0.1,0.5,1,2 \mathrm{ng} / \mathrm{mL}$ ) of $20 \mathrm{HA}$ standards containing 4,7,8-TriMeIQx at $1 \mathrm{ng} / \mathrm{mL}$ in methanol were prepared separately. However, due to presence of high concentrations of norharman and harman in duck samples, two more concentrations ( 5 and $10 \mathrm{ng} / \mathrm{mL}$ ) containing 4,7,8-Tri-MeIQx (1 ng/mL) were also prepared. Then a portion $(40 \mu \mathrm{L})$ of each COP concentration was collected, poured into a vial, derivatized, reacted at $25^{\circ} \mathrm{C}$ in the dark for $1 \mathrm{~h}$ and injected into GC-MS for preparation of COP standard curves by plotting concentration ratio against area ratio. Similarly, the HA standard curves were prepared by plotting concentration ratio against quantitative ion intensity ratio after injection into UPLC-MS/MS. Then the linear regression equations and $r^{2}$ of both COPs and HAs were obtained, and the contents were calculated using a formula as described in several previous studies $[2,5]$.

\subsection{Statistical analysis}

All the data were analyzed by ANOVA for variance analysis and Duncan's multiple range test for significance in mean comparison $(p<0.05)$ by the statistical analysis system [23]. Also, the correlation between COPs and HAs in roast duck was conducted by regression analysis.

\section{Results and discussion}

\subsection{Separation and identification of COPs by GC-MS and HAs by UPLC-MS/MS}

Based on the method described under Materials and methods section, a total of 7 COP standards, $5 \alpha$ cholestane (internal standard) and cholesterol were separated within $14 \mathrm{~min}$ and their detection carried out using SIM mode by using the specific $\mathrm{m} / \mathrm{z}$ ratios shown in Fig. 2. The identification of COPs was made by SIM mode instead of full scan mode (totalion chromatogram, TIC) as the former was reported to show higher sensitivity than the latter $[4,18]$. Likewise, by adopting the separation and detection conditions described above, a total of 21 HA standards including 4,7,8-TriMeIQx (internal standard) were separated within $4.5 \mathrm{~min}$, while their detection accomplished by using a triple quadrupole tandem mass spectrometry in UPLC-MS/MS system. The precursor ions $(\mathrm{m} / \mathrm{z})$ and product ions $(\mathrm{m} / \mathrm{z})$ for both confirmation and quantitation along with corresponding collision energy $(\mathrm{V})$ for each HA were shown in Table 1 (see Fig. 3).

\subsection{Method validation of COPS}

Table S1 shows LOD, LOQ, intra-day and interday variability and recovery of 7 COPs detected by GC-MS. The LOD of 7 COPs ranged from 0.005 to $0.3 \mu \mathrm{g} / \mathrm{mL}$, while the LOQ from 0.01 to $0.8 \mu \mathrm{g} / \mathrm{mL}$. 


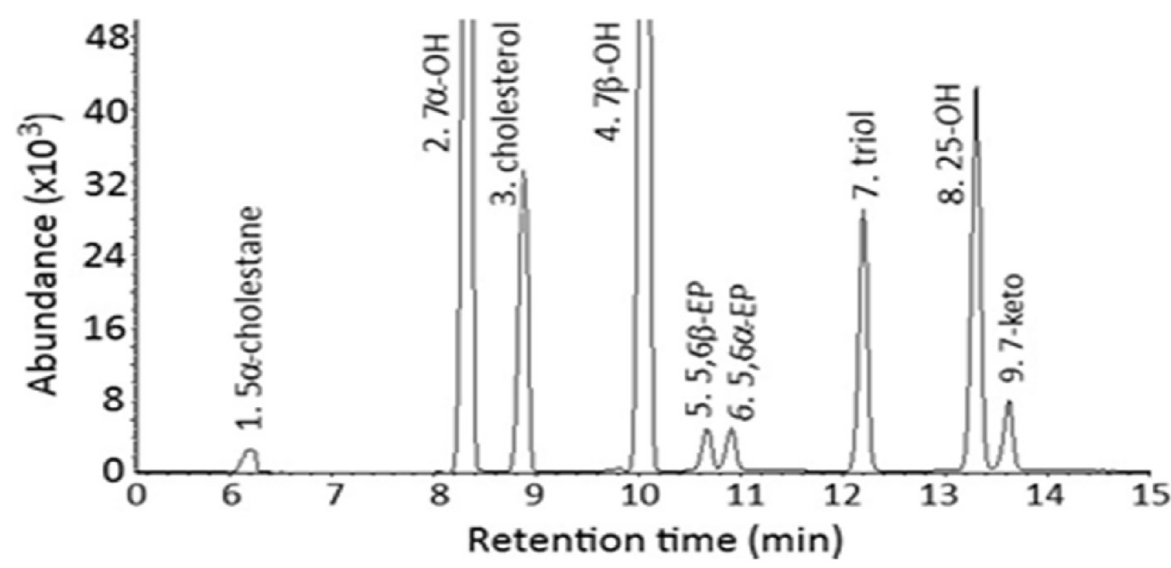

\begin{tabular}{|c|c|c|}
\hline Peak no. & Retention time (min) & $\mathrm{m} / \mathrm{z}$ ratio $(\mathrm{SIM} \text { mode })^{\mathrm{a}, \mathrm{b}}$ \\
\hline 1 & 6.13 & $\underline{217.2}, \underline{357.4}, \underline{372.4}$ (Group 1) \\
\hline 2 & 8.35 & $\underline{456.5}, \underline{458.5}$ (Group 2) \\
\hline 3 & 8.81 & $\underline{329.3}, \underline{353.3}, \underline{368.4}, \underline{443.4}, \underline{458.5}$ (Group 3) \\
\hline 4 & 10.07 & $\overline{456.4}, \overline{458.5}(\overline{G r o u p} 4)$ \\
\hline 5 & 10.68 & $329.3, \underline{356.4}, 368.4, \underline{384.3}, 459.4, \underline{474.5}$ (Group 5) \\
\hline 6 & 10.94 & $329.3, \underline{356.4}, 368.4, \underline{384.3}, 459.4, \underline{474.5}$ (Group 5) \\
\hline 7 & 12.22 & $321.3, \underline{403.4}, \underline{456.4}, 546.5$ (Group 6) \\
\hline 8 & 13.32 & $\underline{131.1}, \underline{271.3}, 327.3,367.3,456.4$ (Group 7) \\
\hline 9 & 13.69 & 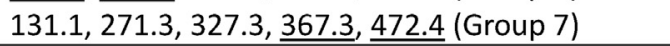 \\
\hline
\end{tabular}

Fig. 2. GC-MS chromatogram of 7 COP standards, cholesterol and internal standard ( $5 \alpha$-cholestane) detected by SIM mode along with the major ion peaks used for their identification. The standards mixture contained 5 ppm of each COP, cholesterol and $5 \alpha$-cholestane.

This outcome is similar to a recent study by $\mathrm{Hsu} \&$ Chen [24], reporting the LOD of 7 COPs to be from 0.005 to $0.3 \mu \mathrm{g} / \mathrm{mL}$ and the LOQ from 0.02 to $0.9 \mu \mathrm{g} /$ $\mathrm{mL}$.

In duck skin, the CV of the intra-day and inter-day variability were respectively ranged from 0.03 to $7.23 \%$ and 0.54 to $7.46 \%$, while in duck meat, the CV were from 0.87 to $9.85 \%$ and $0.87-9.85 \%$ (Table S1). These data are in agreement with a report issued by TFDA [25], showing the acceptable CV of the intraday variability should be $<10 \%$ whereas the interday variability should be $<14 \%$ when the analyte concentration $\geq 1 \mathrm{ppm}$. The recovery of 7 COPs in duck skin ranged from 91.5 to $99.1 \%$ at low level $(1 \mu \mathrm{g} / \mathrm{g})$ and from 88.7 to $102.8 \%$ at high level $(10 \mu \mathrm{g} /$ $\mathrm{g}$ ), while in duck meat, the recovery of 7 COPs ranged from 87.3 to $98.6 \%$ at low level $(1 \mu \mathrm{g} / \mathrm{g})$ and from 87.6 to $100.2 \%$ at high level $(10 \mu \mathrm{g} / \mathrm{g})$ (Table S1). A similar outcome was reported by Chiu et al. [2], showing the recovery of 7 COPs in meat to be from 90.6 to $105.6 \%$. In addition, the recovery data shown in this study is comparable to that obtained by using a silica-SPE method for extraction and purification of COPs in marinated meat and egg as reported by
Lee et al. [18]. Collectively, all the method validation data shown in this study further demonstrated that both high precision and accuracy was attained by using the QuEChERS method in this study.

\subsection{Matrix effect of COPs}

Fig. 4 shows the matrix effects of 7 COPs in duck skin and meat, with the former ranging from 3.21 to $21.29 \%$ and the latter from 15.24 to $27.58 \%$. Obviously duck meat showed a larger matrix effect than duck skin, which should be due to the presence of a more complicated matrix of the former. Of the various COPs, 7-keto possessed the largest matrix effect in both duck skin $(21.29 \%)$ and duck meat $(27.58 \%)$. Similarly, Georgiou et al. [26] also reported the matrix effects of 7 COPs in chicken meat to be from -3.39 to $25.58 \%$. Accordingly, the matrix effect usually refers to signal enhancement or suppression during GC-MS or LC-MS/MS and can be ignored when the level was $\pm 15 \%$ [27]. The larger matrix effect of 4 COPs $(7 \alpha-\mathrm{OH}$, triol, $25-\mathrm{OH}, 7-$ keto $)$ in duck skin and 7 COPs in duck meat should be due to co-extraction of more impurities from duck meat 


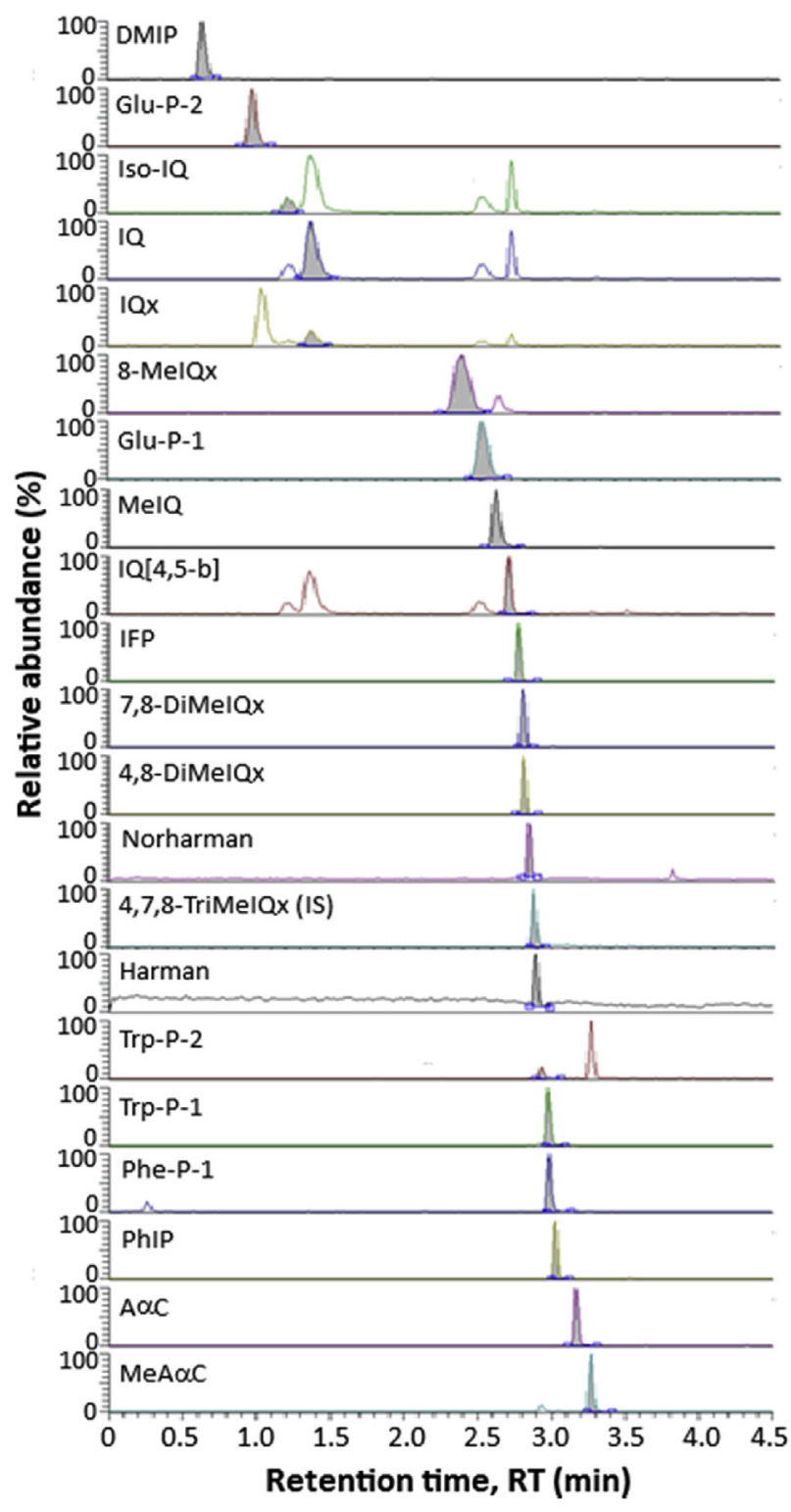

Fig. 3. UPLC-MS/MS chromatograms of $20 \mathrm{HA}$ standards and one internal standard $(4,7,8$-TriMeIQx) detected by SRM mode. The standards mixture contained 5 ppb of each HA and 4,7,8-TriMeIQx. In all overlaid chromatograms, the targeted HA corresponds to the integrated peak.

by the QuEChERS method employed in our study. Nevertheless, the recovery of 7 COPs was acceptable for quantitation.

\subsection{Method validation of HAs}

The LOD, LOQ, intra-day and inter-day variability, and recovery of HAs in duck skin and meat are shown in Table S2. In duck skin, the LOD ranged from 0.005 to $0.05 \mathrm{ng} / \mathrm{g}$ and the LOQ from 0.01 to $0.05 \mathrm{ng} / \mathrm{g}$, while in duck meat, the LOD ranged from 0.004 to $0.04 \mathrm{ng} / \mathrm{g}$ and the LOQ from 0.005 to $0.05 \mathrm{ng} / \mathrm{g}$. Of the various HAs, the LOD and LOQ of harman, norharman and Trp-P-1 were not determined in duck skin and meat as they were originally present in small amounts in duck samples. The average recovery of 20 HAs in duck skin ranged from 57.2 to $113.2 \%$ at low level $(1 \mathrm{ng} / \mathrm{g})$ and from 64.3 to $117.9 \%$ at high level $(10 \mathrm{ng} / \mathrm{g}$ ) (Table S2). While in duck meat, the recovery ranged from 50.0 to $104.7 \%$ at low level $(1 \mathrm{ng} / \mathrm{g})$ and from 62.8 to $105.6 \%$ at high level $(10 \mathrm{ng} / \mathrm{g})$ (Table S2). Most importantly, all the recovery data meet the rule set by TFDA [25], reporting the acceptable recovery to be within $50-125 \%$ when the analyte concentration was $\leq 0.001 \mathrm{ppm}$. Obviously the method used in this study possessed high accuracy.

Both the intra-day and inter-day variability of 20 HAs in duck skin and meat is also shown in Table S2. In duck skin, the HA contents ranged from 0.767 to $1.044 \mathrm{ng} / \mathrm{g}$ and the CV from 11.51 to $24.55 \%$ for the intra-day variability, while for the inter-day variability, the HA contents ranged from 0.756 to $1.063 \mathrm{ng} / \mathrm{g}$ and the CV from 6.79 to $20.7 \%$. Likewise, in duck meat, the HA contents ranged from 0.783 to $1.075 \mathrm{ng} / \mathrm{g}$ and the CV from 8.82 to $28.81 \%$ for the intra-day variability, while for the inter-day variability, the HA contents ranged from 0.813 to $1.121 \mathrm{ng} / \mathrm{g}$ and the CV from 7.59 to $23.80 \%$. Also, all the intra-day and inter-day variability data meets the requirements set by TFDA [25], reporting the acceptable CV of the intra-day variability to be $<35 \%$ and the inter-day variability to be $<36 \%$ when the analyte concentration $\leq 0.001 \mathrm{ppm}$. Apparently the method employed in this study exhibited high precision.

\subsection{Matrix effect of HAs}

The matrix effects of 17 HAs in duck skin and meat are shown in Fig. 4, with the former ranging from $-10.10 \%$ to $-57.6 \%$ and the latter from $-18.33 \%$ to $-57.00 \%$. Of the various HAs, 8 -MeIQx showed the least matrix effect $(-10.10 \%)$ and $\mathrm{MeA} \alpha \mathrm{C}$ showed the most pronounced matrix effect $(-57.60 \%)$ for duck skin, while for duck meat, iso-IQ showed the lowest matrix effect $(-18.33 \%)$ and TrpP-2 the most notable matrix effect $(-57.00 \%)$. As mentioned above, the matrix effect of LC-MS/MS often refers to signal enhancement or suppression of analytes, which can be ignored when the level was $\pm 15 \%$ [27]. By comparison, the matrix effect of 20 HAs in duck skin and meat was higher than that in cooking oil [22], which can be attributed to the coextraction of some more impurities in our study and 

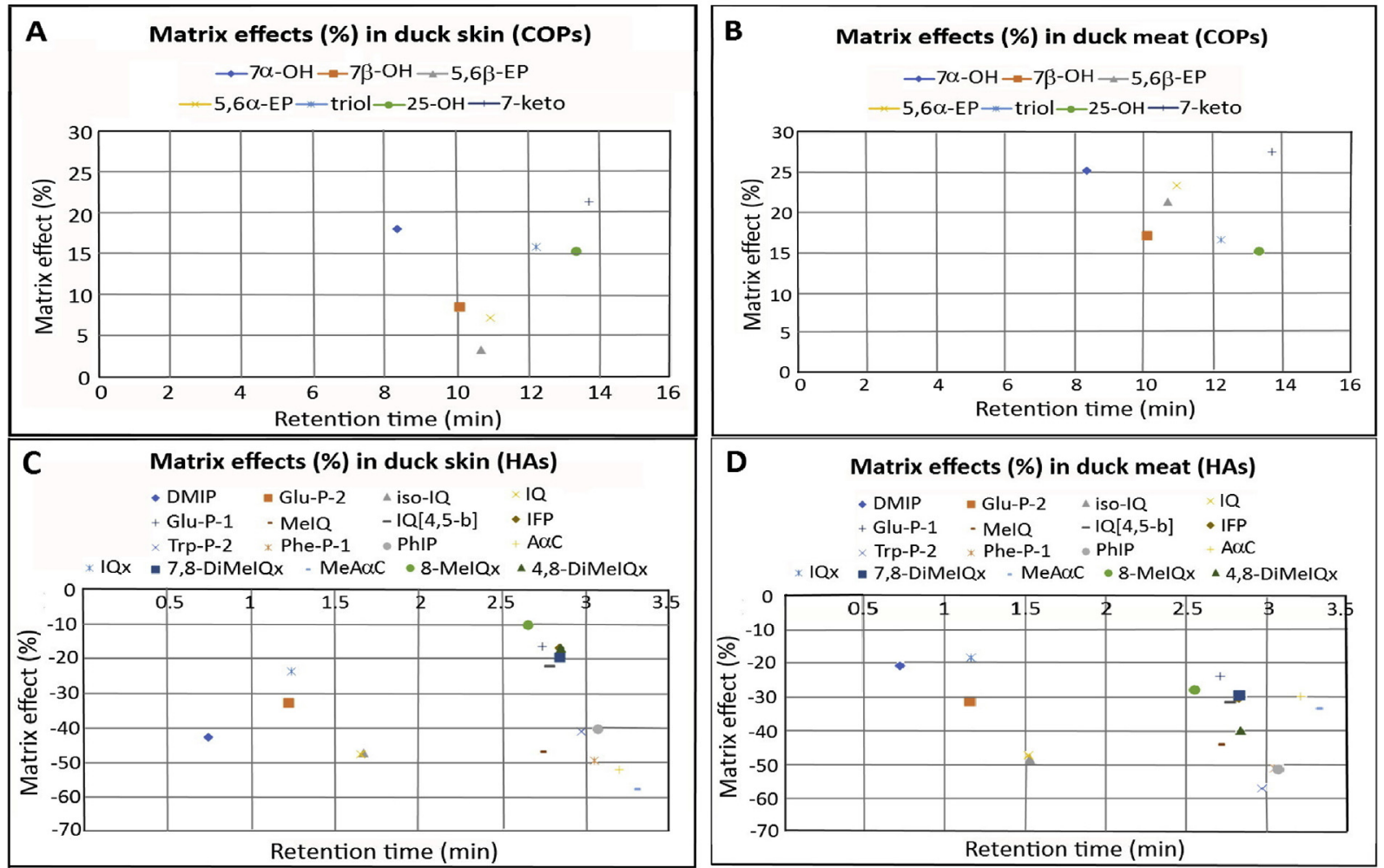

Fig. 4. Matrix effects of 7 COPs $(A, B)$ and $17 \mathrm{HAs}(C, D)$ in duck skin and meat. Matrix effect was determined by using the formula, ME $(\%)=($ slope of MCC-slope of SCC/slope of SCC) $\times 100$, where SCC is the standard calibration curve obtained by mixing 5 concentrations of each COP $(0.4,1.2,2$, $4,10 \mu \mathrm{g} / \mathrm{mL})$ with $5 \alpha$-cholestane $(2 \mu \mathrm{g} / \mathrm{mL}), 40 \mu \mathrm{L}$ Sylon BTZ for derivatization in dark for $1 \mathrm{~h}$ and injecting into GC-MS for analysis, while MCC is the matrix-matched calibration curve obtained by adding the same 5 concentrations and $5 \alpha$-cholestane to boiled duck breast extract (skin and meat), followed by extraction, purification, derivatization and injection into GC-MS for analysis. For matrix effect determination of 20 HAs, 5 concentrations of each HA $(0.05,0.1,0.5,1,2 \mathrm{ng} / \mathrm{mL})$ was mixed with 4,7,8-TriMeIQx (1 $\mathrm{ng} / \mathrm{mL})$ for UPLC-MS/MS analysis to obtain SCC, while the MCC was obtained by adding the mixture of same 5 concentrations and 4,7,8-TriMeIQx to boiled duck breast extract (skin and meat), followed by extraction, purification and injection into UPLC-MS/MS for analysis. For duck skin and meat, the matrix effect respectively ranged from 3.21 to $21.29 \%$ and 15.24 to $27.58 \%$ for COPs (Fig. 4 A, B) as well as -10.10 to $-57.60 \%$ and -18.33 to $-57.00 \%$ for HAs (Fig. 4C, D).

the difference in food matrix. Nonetheless, the recovery of 20 HAs was acceptable for quantitation.

\subsection{Effects of processing methods on COP formation in roast duck}

The effects of processing methods on COP formation in roast duck are shown in Table 2. Only $7 \alpha-$ $\mathrm{OH}, 7 \beta-\mathrm{OH}$ and 7-keto were detected in raw duck skin with a low level of $0.729,0.935$ and $0.617 \mu \mathrm{g} / \mathrm{g}$, respectively. However, following spraying with maltose, two more COPs, triol $(0.650 \mu \mathrm{g} / \mathrm{g})$ and 25 $\mathrm{OH}(0.740 \mu \mathrm{g} / \mathrm{g})$ were formed, with the total COPs in duck skin ranging from 3.750 to $4.718 \mu \mathrm{g} / \mathrm{g}$ after roasting. By comparison, superheated steam generated the highest level of total COPs $(4.718 \mu \mathrm{g} /$ g) in duck skin, followed by traditional oven $(3.802 \mu \mathrm{g} / \mathrm{g})$ and fan oven $(3.750 \mu \mathrm{g} / \mathrm{g})$. However, both traditional oven and fan oven showed no significant difference $(p>0.05)$ in total COPs. Likewise, a low level of $7 \alpha-\mathrm{OH}(1.465 \mu \mathrm{g} / \mathrm{g}), 7 \beta-\mathrm{OH}(1.302 \mu \mathrm{g} /$ g) and 7-keto $(0.782 \mu \mathrm{g} / \mathrm{g})$ was detected in raw duck meat. Following spraying with maltose, 3 more COPs, $5,6 \beta$-EP $(0.858 \mu \mathrm{g} / \mathrm{g})$, triol $(0.650 \mu \mathrm{g} / \mathrm{g})$ and 25 $\mathrm{OH}(0.749 \mu \mathrm{g} / \mathrm{g})$ were produced. Also, a total of 7 COPs were generated in duck meat by fan oven and traditional oven, while 5 COPs formed by superheated steam oven. Comparatively, both superheated steam oven and traditional oven generated significantly higher levels of total COPs $(26.148 \mu \mathrm{g} / \mathrm{g}$ and $26.066 \mu \mathrm{g} / \mathrm{g})$ than fan oven $(16.833 \mu \mathrm{g} / \mathrm{g})$, with $7 \alpha-\mathrm{OH}, 7 \beta-\mathrm{OH}$ and 7 -keto dominating in all the duck meat samples. The formation of $7 \alpha-\mathrm{OH}$ and $7 \beta-\mathrm{OH}$ should be due to reduction of the initial cholesterol oxidation products $7 \alpha-\mathrm{OOH}$ and $7 \beta-$ $\mathrm{OOH}$, respectively [4], while 7-keto due to dehydration of $7 \alpha-\mathrm{OOH}$ or $7 \beta-\mathrm{OOH}$. Furthermore, a much lower level of total COPs was shown in roast duck skin than in roast duck meat, which should be due to oil dripping of the former during roasting, resulting in cholesterol loss and subsequent less formation of COPs. According to a report by USDA 
Table 2. COP contents $(\mu g / g)^{a}$ in roast duck skin and meat as affected by different processing methods.

\begin{tabular}{|c|c|c|c|c|c|}
\hline \multirow[t]{2}{*}{$\overline{\mathrm{COPs}}$} & \multicolumn{5}{|l|}{ Duck skin $^{b}$} \\
\hline & Raw duck & Sprayed with maltose & Traditional oven & Superheated steam oven & Fan oven \\
\hline $7 \alpha-\mathrm{OH}$ & $0.729 \pm 0.039^{\mathrm{BC}}$ & $0.880 \pm 0.015^{\mathrm{A}}$ & $0.733 \pm 0.004^{\mathrm{BC}}$ & $0.756 \pm 0.002^{\mathrm{AB}}$ & $0.702 \pm 0.002^{C}$ \\
\hline $7 \beta-\mathrm{OH}$ & $0.935 \pm 0.015^{\mathrm{C}}$ & $0.987 \pm 0.010^{\mathrm{A}}$ & $0.947 \pm 0.002^{\mathrm{BC}}$ & $0.967 \pm 0.002^{\mathrm{B}}$ & $0.932 \pm 0.001^{\mathrm{C}}$ \\
\hline $5,6 \beta-E P$ & $\mathrm{nd}^{\mathrm{c}}-\mathrm{n}$ & nd & nd & $0.861 \pm 0.006^{\mathrm{A}}$ & nd \\
\hline $5,6 \alpha-E P$ & nd & nd & nd & nd & nd \\
\hline triol & nd & $0.650 \pm 0.001^{\mathrm{A}}$ & $0.647 \pm 0.002^{\mathrm{A}}$ & $0.653 \pm 0.001^{\mathrm{A}}$ & $0.645 \pm 0.000^{\mathrm{A}}$ \\
\hline $25-\mathrm{OH}$ & nd & $0.740 \pm 0.000^{B}$ & $0.746 \pm 0.002^{\mathrm{AB}}$ & $0.748 \pm 0.005^{\mathrm{A}}$ & $0.748 \pm 0.002^{\mathrm{A}}$ \\
\hline 7-keto & $0.617 \pm 0.009$ & $0.705 \pm 0.023^{\mathrm{A}}$ & $0.729 \pm 0.025^{\mathrm{A}}$ & $0.734 \pm 0.095^{\mathrm{A}}$ & $0.722 \pm 0.070^{\mathrm{A}}$ \\
\hline Total & $2.281 \pm 0.045^{\mathrm{E}}$ & $3.883 \pm 0.049^{\mathrm{D}}$ & $3.802 \pm 0.015^{\mathrm{D}}$ & $4.718 \pm 0.089^{\mathrm{C}}$ & $3.750 \pm 0.068^{\mathrm{D}}$ \\
\hline \multirow[t]{2}{*}{$\overline{\mathrm{COPs}}$} & \multicolumn{5}{|l|}{ Duck meat $^{b}$} \\
\hline & Raw duck & Sprayed with maltose & Traditional oven & Superheated steam oven & Fan oven \\
\hline$\overline{7 \alpha-\mathrm{OH}}$ & $1.465 \pm 0.129^{\mathrm{D}}$ & $0.657 \pm 0.001^{\mathrm{E}}$ & $7.213 \pm 0.036^{\mathrm{B}}$ & $8.085 \pm 0.174^{\mathrm{A}}$ & $4.524 \pm 0.031^{\mathrm{C}}$ \\
\hline $7 \beta-\mathrm{OH}$ & $1.302 \pm 0.068^{\mathrm{D}}$ & $0.910 \pm 0.002^{\mathrm{E}}$ & $5.459 \pm 0.078^{B}$ & $6.147 \pm 0.097^{\mathrm{A}}$ & $3.501 \pm 0.008^{C}$ \\
\hline $5,6 \beta$-EP & nd & $0.858 \pm 0.009^{\mathrm{C}}$ & $1.636 \pm 0.028^{\mathrm{A}}$ & nd & $1.424 \pm 0.006^{\mathrm{B}}$ \\
\hline $5,6 \alpha-\mathrm{EP}$ & nd & nd & $0.860 \pm 0.026^{\mathrm{A}}$ & nd & $0.813 \pm 0.012^{\mathrm{A}}$ \\
\hline triol & nd & $0.650 \pm 0.000^{C}$ & $0.677 \pm 0.000^{\mathrm{A}}$ & $0.676 \pm 0.003^{\mathrm{A}}$ & $0.660 \pm 0.003^{B}$ \\
\hline $25-\mathrm{OH}$ & nd & $0.749 \pm 0.015^{\mathrm{A}}$ & $0.770 \pm 0.004^{\mathrm{A}}$ & $0.770 \pm 0.006^{\mathrm{A}}$ & $0.759 \pm 0.003^{\mathrm{A}}$ \\
\hline 7-keto & $0.782 \pm 0.127^{\mathrm{D}}$ & $0.651 \pm 0.008^{\mathrm{D}}$ & $9.451 \pm 0.298^{B}$ & $10.469 \pm 0.045^{\mathrm{A}}$ & $5.151 \pm 0.159^{C}$ \\
\hline Total & $3.550 \pm 0.325^{\mathrm{D}}$ & $4.475 \pm 0.020^{C}$ & $26.066 \pm 0.414^{\mathrm{A}}$ & $26.148 \pm 0.216^{\mathrm{A}}$ & $16.833 \pm 0.197^{\mathrm{B}}$ \\
\hline
\end{tabular}

${ }^{\text {a }}$ Mean of duplicate analyses \pm standard deviation.

b Symbols bearing different capital letters (A-E) in the same row are significantly different $(\mathrm{p}<0.05)$.

${ }^{\mathrm{c}}$ nd $=$ not detected (below the limit of detection).

[28], raw duck meat contains a slightly higher level of cholesterol than raw duck skin. Thus, during roasting, the oil loss in duck skin can be accompanied by cholesterol loss. In a previous study Chen et al. [29] also reported that the total COPs in pig feet meat was higher than in pig feet skin. In addition, the presence of phospholipid in muscle meat membrane is rich in polyunsaturated fatty acids, which may be released to promote cholesterol oxidation following cell membrane destruction during heating [30].

Table 3 shows COP contents in roast duck purchased on Taiwan's market, with the total COPs ranging from 3.743 to $4.841 \mu \mathrm{g} / \mathrm{g}$ in duck skin and from 4.040 to $9.856 \mu \mathrm{g} / \mathrm{g}$ in duck meat. Also, in roast duck skin, a total of 7 COPs were detected in sample D01, while 6 COPs in samples D02, D03, D04, D05, D06, D07, D08 and D10, and 5 COPs in sample D09. While in roast duck meat, triol and $25-\mathrm{OH}$ remained undetected in all the samples. Instead, a total of 5 COPs including $7 \alpha-\mathrm{OH}, 7 \beta-\mathrm{OH}, 5,6-\beta$-EP $5,6 \alpha-\mathrm{EP}$ and 7-keto were present in all the duck meat samples (Table 3). By comparison, the level of total COPs was higher in commercial duck meat than in commercial duck skin, which should be due to oil dripping in duck skin during roasting as explained above. Furthermore, the difference in total COPs among various roast duck skin or meat samples was small, probably because of a more consistent commercial roasting condition employed. Nevertheless, it was shown the levels of total COPs in commercial duck meat was much lower than the experimental while commercial duck skin showed similar results to the experimental. It may be postulated that in commercial duck meat samples, a gradual dripping of oil occurs from the hanging roast duck on food stands leading to loss of cholesterol and COPs, due to delay in purchase time by consumers. However, in this study this time-lag is avoided in our roast duck as fresh roast duck meat samples were prepared for COPs analysis. On the other hand, a significant amount of cholesterol loss occurred in skin by fast oil dripping during roasting of the commercial duck and experimental duck, resulting in a similar formation of total COPs.

\subsection{Effect of processing method on HA formation in roast duck}

The HA formation in roast duck as affected by different processing methods are shown in Table 4. Only a small amount of norharman $(0.06 \mathrm{ng} / \mathrm{g})$ and harman $(0.301 \mathrm{ng} / \mathrm{g})$ were present in raw duck skin. However, the total HAs rose to $0.562 \mathrm{ng} / \mathrm{g}$ following spraying with maltose, accompanied by generation of some more varieties of HAs including MeIQ, 4,8DiMeIQx, 7,8-DiMeIQx and PhIP. Only a slight difference in total HAs was found in duck skin roasted in fan oven $(1.328 \mathrm{ng} / \mathrm{g})$, traditional oven (1.032 ng/g) and superheated steam oven (1.027 ng/ 


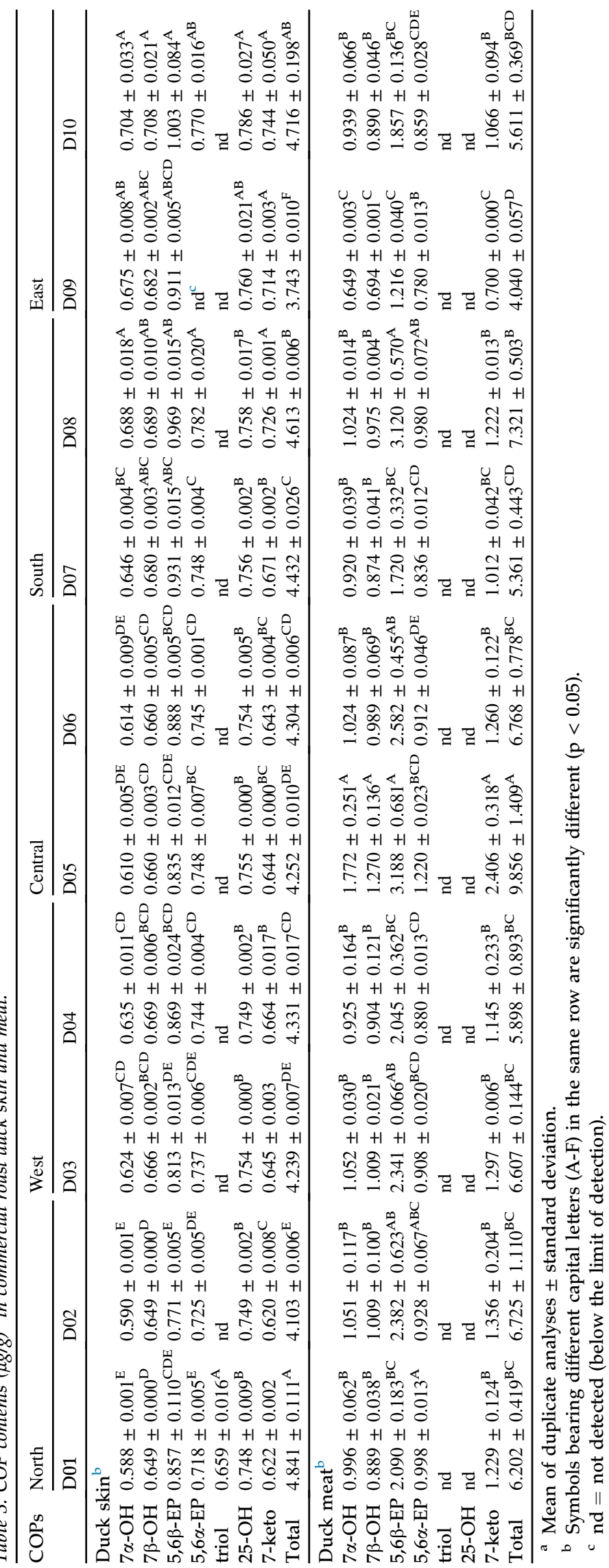

g), with the total HAs from the latter two ovens showing no significant difference $(p>0.05)$. Also, a total of 10 HAs were detected in duck skin roasted in superheated steam oven, 12 HAs in traditional oven and 13 HAs in fan oven.

Like duck skin, a small amount of norharman $(0.067 \mathrm{ng} / \mathrm{g})$ and harman $(0.054 \mathrm{ng} / \mathrm{g})$ was present in raw duck meat. However, the formation of norharman and harman showed no significant difference ( $p>0.05$ ) following spraying with maltose. Also, both traditional oven and fan oven produced significantly higher levels of total HAs $(0.787 \mathrm{ng} / \mathrm{g}$ and $0.611 \mathrm{ng} / \mathrm{g}$ ) compared to superheated steam oven $(0.269 \mathrm{ng} / \mathrm{g})$. Interestingly, only $3 \mathrm{HAs}$ (norharman, harman, Trp-P-1) were generated in duck meat roasted with superheated steam oven, while 9 HAs (norharman, harman, Trp-P-1, MeIQ, 4,8-DiMeIQx, 7,8-DiMeIQx, IFP, PhIP, MeA $\alpha$ C) with traditional oven, and 7 HAs (norharman, harman, Trp-P-1, MeIQ, 4,8-DiMeIQx, Trp-P-2 and PhIP) with fan oven.

\subsection{Comparison of COP and HA formation in roast duck}

The formation of 5,6 6 -EP in duck skin roasted by superheated steam oven resulted in the highest level of total COPs, which should be due to direct contact of duck skin with moist heat causing more formation of $7 \beta-\mathrm{OOH}$ from cholesterol. This is because of the smaller steric hindrance of $7 \beta-\mathrm{OOH}$ compared to $7 \alpha-\mathrm{OOH}$ [31]. However, both 5,6 $\alpha$-EP and 5,6 3 -EP were not formed in duck skin roasted in traditional and fan oven methods, which can be due to low cholesterol level in duck skin caused by oil dripping during roasting as mentioned above.

It was shown that roasting duck meat by traditional and fan oven methods resulted in the formation of both 5,6 $\alpha$-EP and 5,6 6 -EP, which should be due to the cholesterol level in duck meat sufficiently high enough to form 5,6 $\alpha$-EP and 5,6 6 -EP in the presence of $7 \alpha-\mathrm{OOH}$ and $7 \beta-\mathrm{OOH}$, respectively. However, the high specific heat of superheated steam $\left(0.48 \mathrm{cal} / \mathrm{g} \cdot{ }^{\circ} \mathrm{C}\right)$ in superheated steam oven should have caused complete reduction of $7 \alpha-\mathrm{OOH}$ and $7 \beta-\mathrm{OOH}$ to form $7 \alpha-\mathrm{OH}$ and $7 \beta-\mathrm{OH}$ or dehydration to form 7-keto, thereby preventing the for-

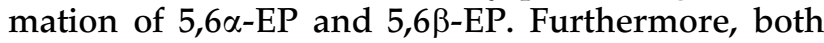
$5,6 \alpha-\mathrm{EP}$ and 5,6 $\beta$-EP may also undergo hydration to form triol in a superheated oven under acidic condition. This is evident from the significantly high levels of $7 \alpha-\mathrm{OH}, 7 \beta-\mathrm{OH}$ and $7-$ keto formed in duck meat roasted by superheated steam oven than by the other two roasting methods (Table 2). 


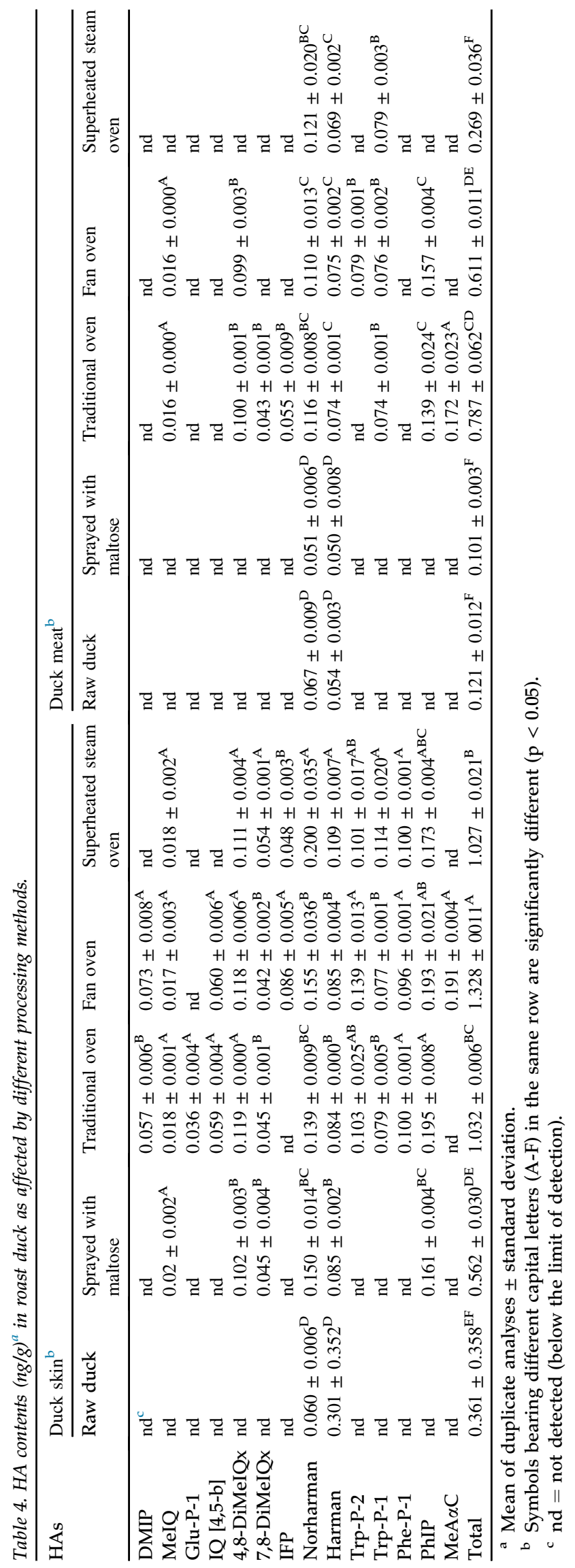

Comparatively, duck skin contained a higher level of total HAs than duck meat after roasting, which should be due to direct contact of the former with heat. Also, the moisture content in skin is lower than meat during roasting because of evaporation, which in turn resulted in higher level of total HAs in skin. Furthermore, the difference in variety and amount of HAs formed between processing methods is probably due to heating principle, i.e, the specific heat of hot air (dry heat) in fan oven is $0.17 \mathrm{cal} / \mathrm{g} \cdot{ }^{\circ} \mathrm{C}$ while that of superheated steam (wet heat) is $0.48 \mathrm{cal} / \mathrm{g} \cdot{ }^{\circ} \mathrm{C}$ in steam oven. More specifically, compared to traditional and fan ovens, the formation of DMIP and IQ $[4,5-b]$ in skin as well as MeIQ, 4,8-DiMeIQx and PhIP in meat are prevented by roasting under high specific heat in superheated steam oven. In an earlier study dry heating was reported to favor formation of $\mathrm{A} \alpha \mathrm{C}$ and PhIP, whereas wet heating favored formation of MeIQx and IQx [32]. Similarly, in a meat model system heated under wet and dry conditions, the former was reported to favor MeIQx formation while the latter favored formation of PhIP, IFP, TMIP and DMIP [33]. Apparently, the difference in heating system, temperature and time can affect the variety of HAs formed.

Table 5 shows HA contents in duck skin and meat from roast duck purchased on Taiwan's market. Both norharman and harman dominated in most duck skin and meat samples, with the level of total HAs ranging from 0.867 to $6.880 \mathrm{ng} / \mathrm{g}$ for the former (duck skin) and from 0.325 to $2.89 \mathrm{ng} / \mathrm{g}$ for the latter (duck meat). Comparatively, a much higher level and some more varieties of HAs were generated in duck skin than in duck meat, which can be attributed to direct contact of the former with heat source as explained above. In a similar study Liao et al. [34] determined HA contents in roast duck purchased on China's market and 4 HAs including norharman $(7.24 \mathrm{ng} / \mathrm{g})$, harman $(6.12 \mathrm{ng} / \mathrm{g})$, Trp-P-2 $(0.19 \mathrm{ng} / \mathrm{g})$ and PhIP $(1.49 \mathrm{ng} / \mathrm{g})$ were detected in duck skin, while only 2 HAs, norharman $(1.28 \mathrm{ng} / \mathrm{g})$ and harman $(0.85 \mathrm{ng} / \mathrm{g})$ detected in duck meat. By comparison, in our study some more varieties of HAs were detected in both duck skin and duck meat, which should be due to the difference in the extraction and purification method and sensitivity of the instrument used for HAs determination in roast duck.

To determine the extent of correlation between formation of COPs and HAs in duck by different roasting methods, the regression analysis was carried out and the results are shown in Table 6. For roast duck skin, the correlation coefficient (r) was 0.956, 0.920 and 0.982 for traditional oven, fan oven and superheated steam oven, respectively, all of which 
Table 5. HA contents $(n g / g)^{a, b}$ in commercial roast duck skin and meat.

\begin{tabular}{|c|c|c|c|c|c|c|c|c|c|c|}
\hline HAs & D01 & D02 & D03 & D04 & D05 & D06 & D07 & D08 & D09 & D10 \\
\hline \multicolumn{11}{|l|}{ Duck skin } \\
\hline DMIP & $\operatorname{trace}^{c}$ & $0.393 \pm 0.118^{\mathrm{ABC}}$ & $0.230 \pm 0.008^{\mathrm{C}}$ & trace & $0.228 \pm 0.052^{\mathrm{BC}}$ & $0.626 \pm 0.412^{\mathrm{AB}}$ & $0.413 \pm 0.042^{\mathrm{ABC}}$ & $0.013 \pm 0.018^{\mathrm{D}}$ & $0.030 \pm 0.026^{\mathrm{D}}$ & $0.851 \pm 0.220^{\mathrm{A}}$ \\
\hline iso-IQ & trace & $0.568 \pm 0.122^{\mathrm{A}}$ & trace & trace & $0.625 \pm 0.035^{\mathrm{A}}$ & $0.574 \pm 0.811^{\mathrm{A}}$ & $\mathrm{nd}^{\mathrm{d}}$ & nd & $0.495 \pm 0.019^{\mathrm{A}}$ & nd \\
\hline IQ & nd & nd & nd & nd & nd & nd & $0.342 \pm 0.011$ & nd & nd & nd \\
\hline 8-MeIQx & trace & $0.438 \pm 0.153^{B}$ & $0.417 \pm 0.005^{\mathrm{B}}$ & $0.289 \pm 0.409^{\mathrm{B}}$ & trace & $0.492 \pm 0.125^{\mathrm{AB}}$ & $0.520 \pm 0.054^{\mathrm{AB}}$ & trace & $0.109 \pm 0.058^{\mathrm{B}}$ & $1.247 \pm 0.607^{\mathrm{A}}$ \\
\hline MeIQ & nd & $0.292 \pm 0.001^{\mathrm{A}}$ & trace & trace & trace & trace & trace & nd & trace & nd \\
\hline $\mathrm{IQ}[4,5-\mathrm{b}]$ & nd & $0.312 \pm 0.203^{\mathrm{A}}$ & trace & trace & $0.214 \pm 0.030^{\mathrm{A}}$ & trace & $0.340 \pm 0.055^{\mathrm{A}}$ & $0.212 \pm 0.143^{\mathrm{A}}$ & trace & $0.441 \pm 0.190^{\mathrm{A}}$ \\
\hline IFP & trace & $0.284 \pm 0.172^{\mathrm{A}}$ & $0.170 \pm 0.021^{\mathrm{A}}$ & $0.132 \pm 0.186^{\mathrm{A}}$ & $0.080 \pm 0.011^{\mathrm{A}}$ & $0.434 \pm 0.340^{\mathrm{A}}$ & $0.235 \pm 0.076^{\mathrm{A}}$ & trace & trace & $0.270 \pm 0.130^{\mathrm{A}}$ \\
\hline 7,8-DiMeIQx & nd & nd & nd & nd & nd & $0.049 \pm 0.069^{\mathrm{A}}$ & $0.019 \pm 0.025^{\mathrm{A}}$ & nd & nd & $0.022 \pm 0.031^{\mathrm{A}}$ \\
\hline Norharman & $0.418 \pm 0.468^{C}$ & $0.738 \pm 0.187^{\mathrm{BC}}$ & $0.953 \pm 0.030^{\mathrm{BC}}$ & $0.415 \pm 0.586^{\mathrm{C}}$ & $2.584 \pm 0.550^{\mathrm{A}}$ & $1.018 \pm 0.142^{\mathrm{BC}}$ & $1.046 \pm 0.211^{\mathrm{BC}}$ & $1.505 \pm 0.155^{\mathrm{B}}$ & $1.207 \pm 0.723^{\mathrm{BC}}$ & $0.688 \pm 0.308^{\mathrm{BC}}$ \\
\hline Harman & $0.158 \pm 0.052^{B}$ & $0.205 \pm 0.054^{\mathrm{B}}$ & $0.826 \pm 0.040^{\mathrm{AB}}$ & $0.426 \pm 0.427^{\mathrm{AB}}$ & $0.403 \pm 0.037^{\mathrm{AB}}$ & $0.268 \pm 0.086^{\mathrm{AB}}$ & $0.219 \pm 0.048^{\mathrm{B}}$ & $0.249 \pm 0.045^{\mathrm{AB}}$ & $0.758 \pm 0.560^{\mathrm{A}}$ & $0.129 \pm 0.182^{\mathrm{B}}$ \\
\hline Trp-P-2 & nd & nd & nd & trace & trace & trace & nd & nd & $0.564 \pm 0.743^{\mathrm{A}}$ & $0.210 \pm 0.017^{\mathrm{A}}$ \\
\hline Trp-P-1 & $0.188 \pm 0.265^{\mathrm{CD}}$ & $0.238 \pm 0.011^{\mathrm{BCD}}$ & $0.265 \pm 0.003^{\mathrm{AB}}$ & $0.313 \pm 0.170^{\mathrm{BCD}}$ & nd & $0.507 \pm 0.088^{\mathrm{AB}}$ & $0.694 \pm 0.049^{\mathrm{A}}$ & $0.425 \pm 0.022^{\mathrm{ABC}}$ & $0.098 \pm 0.089^{\mathrm{D}}$ & $0.510 \pm 0.186^{\mathrm{AB}}$ \\
\hline Phe-P-1 & nd & nd & nd & trace & nd & trace & trace & trace & nd & $0.070 \pm 0.019$ \\
\hline PhIP & $0.055 \pm 0.078^{B}$ & $0.386 \pm 0.095^{\mathrm{B}}$ & $0.752 \pm 0.024^{B}$ & $0.444 \pm 0.627^{B}$ & $0.199 \pm 0.043^{B}$ & $0.427 \pm 0.066^{\mathrm{B}}$ & $0.745 \pm 0.066^{\mathrm{B}}$ & trace & trace & $2.369 \pm 0.610^{\mathrm{A}}$ \\
\hline $\mathrm{A} \alpha \mathrm{C}$ & $0.048 \pm 0.067^{\mathrm{A}}$ & nd & nd & nd & $0.089 \pm 0.012^{\mathrm{A}}$ & $0.107 \pm 0.028^{\mathrm{A}}$ & $0.048 \pm 0.067^{\mathrm{A}}$ & nd & nd & $0.073 \pm 0.103^{\mathrm{A}}$ \\
\hline Total & $0.867 \pm 0.931^{\mathrm{C}}$ & $3.854 \pm 1.117^{\mathrm{B}}$ & $3.613 \pm 0.250^{\mathrm{B}}$ & $2.019 \pm 2.068^{\mathrm{BC}}$ & $4.422 \pm 0.699^{\mathrm{AB}}$ & $4.502 \pm 1.425^{\mathrm{B}}$ & $4.621 \pm 0.354^{\mathrm{AB}}$ & $2.404 \pm 0.004^{\mathrm{BC}}$ & $3.261 \pm 0.648^{\mathrm{BC}}$ & $6.880 \pm 1.621^{\mathrm{A}}$ \\
\hline \multicolumn{11}{|l|}{ Duck meat } \\
\hline DMIP & trace & trace & trace & trace & nd & nd & trace & nd & Trace & trace \\
\hline iso-IQ & trace & nd & trace & nd & nd & nd & nd & nd & nd & nd \\
\hline 8-MeIQx & trace & nd & $0.290 \pm 0.034^{\mathrm{A}}$ & trace & nd & trace & $0.056 \pm 0.029^{B}$ & nd & nd & nd \\
\hline MeIQ & nd & nd & trace & nd & nd & trace & nd & nd & nd & nd \\
\hline $\mathrm{IQ}[4,5-\mathrm{b}]$ & nd & nd & trace & trace & $0.084 \pm 0.024^{\mathrm{A}}$ & trace & trace & $0.122 \pm 0.033$ & nd & $0.099 \pm 0.008^{\mathrm{A}}$ \\
\hline IFP & trace & nd & trace & nd & nd & nd & nd & nd & nd & nd \\
\hline Norharman & $0.383 \pm 0.303^{\mathrm{BC}}$ & $0.082 \pm 0.018^{\mathrm{C}}$ & $0.987 \pm 0.390^{\mathrm{AB}}$ & $0.168 \pm 0.232^{C}$ & $0.374 \pm 0.108^{\mathrm{BC}}$ & $0.228 \pm 0.178^{C}$ & $0.305 \pm 0.012^{C}$ & $0.368 \pm 0.045^{\mathrm{BC}}$ & $1.296 \pm 0.773^{\mathrm{A}}$ & $0.354 \pm 0.182^{B C}$ \\
\hline Harman & $0.212 \pm 0.178^{B}$ & $0.029 \pm 0.040^{\mathrm{B}}$ & $0.326 \pm 0.120^{\mathrm{A}}$ & $0.069 \pm 0.044^{B}$ & $0.078 \pm 0.006^{\mathrm{B}}$ & $0.048 \pm 0.068^{B}$ & $0.158 \pm 0.014^{B}$ & $0.084 \pm 0.119^{B}$ & nd & nd \\
\hline Trp-P-2 & nd & nd & nd & nd & Trace & nd & nd & nd & nd & trace \\
\hline Trp-P-1 & trace & $0.214 \pm 0.033^{\mathrm{BC}}$ & $0.499 \pm 0.057^{\mathrm{BC}}$ & $0.160 \pm 0.051^{C}$ & nd & $0.213 \pm 0.099^{\mathrm{BC}}$ & $0.675 \pm 0.047^{\mathrm{B}}$ & $0.194 \pm 0.274^{\mathrm{C}}$ & $1.507 \pm 0.484^{\mathrm{A}}$ & $0.354 \pm 0.113^{\mathrm{BC}}$ \\
\hline Phe-P-1 & nd & nd & nd & nd & nd & nd & nd & $0.051 \pm 0.071^{\mathrm{A}}$ & $0.087 \pm 0.122^{\mathrm{A}}$ & nd \\
\hline PhIP & trace & nd & $0.145 \pm 0.002^{\mathrm{A}}$ & nd & nd & nd & trace & nd & trace & trace \\
\hline $\mathrm{A} \alpha \mathrm{C}$ & nd & nd & trace & nd & nd & trace & nd & nd & nd & nd \\
\hline Total & $0.596 \pm 0.361^{\mathrm{B}}$ & $0.325 \pm 0.025^{\mathrm{B}}$ & $2.247 \pm 0.449^{\mathrm{A}}$ & $0.397 \pm 0.327^{\mathrm{B}}$ & $0.536 \pm 0.126^{\mathrm{B}}$ & $0.489 \pm 0.345^{\mathrm{B}}$ & $1.194 \pm 0.053^{\mathrm{B}}$ & $0.819 \pm 0.304^{\mathrm{B}}$ & $2.890 \pm 1.380^{\mathrm{A}}$ & $0.807 \pm 0.038^{\mathrm{B}}$ \\
\hline
\end{tabular}

${ }^{a}$ Mean of duplicate analyses \pm standard deviation.

b Symbols bearing different capital letters (A-D) in the same row are significantly different $(\mathrm{p}<0.05)$

c Trace means HAs levels are higher than or equal to limit of detection (LOD), but below limit of quantitation (LOQ), or negative due to lower HAs level than the background values of calibration curves.

d nd $=$ not detected (below the limit of detection). 
Table 6. Regression analysis for total HAs and COPs in roast duck skin and meat as affected by processing methods.

\begin{tabular}{lllllll}
\hline Roasted duck & Processing method & Total HAs $(\mathrm{ng} / \mathrm{g})$ & Total COPs $(\mu \mathrm{g} / \mathrm{g})$ & $\mathrm{r}^{\mathrm{a}}$ & $\mathrm{r}^{2 \mathrm{~b}}$ & $\mathrm{p}^{\mathrm{v}} \mathrm{value}$ \\
\hline Skin & Traditional oven & 1.032 & 3.802 & 0.956 & 0.914 & 0.189 \\
& Fan oven & 1.328 & 4.718 & 0.920 & 0.847 & 0.256 \\
& Superheated steam oven & 1.027 & 3.750 & 0.982 & 0.965 \\
Meat & Traditional oven & 0.787 & 26.066 & 0.120 \\
& Fan oven & 0.611 & 16.833 & 0.991 & 0.998 & 0.027 \\
& Superheated steam oven & 0.269 & 26.148 & 0.982 & 0.964 \\
\hline
\end{tabular}

${ }^{a}$ Correlation coefficient.

b Coefficient of determination.

${ }^{\mathrm{c}} \mathrm{p}<0.05$ represents significant correlations.

showed no significant correlation $(\mathrm{p}>0.05)$. However, for roast duck meat, the correlation coefficient was 0.999, 0.991 and 0.982 for traditional oven, fan oven and superheated steam oven, respectively, in which only traditional oven showed significant correlation ( $p<0.05$ ), which may be accounted for by a much larger formation of total COPs $(26.066 \mu \mathrm{g} / \mathrm{g})$ and a less formation of total HAs $(0.787 \mathrm{ng} / \mathrm{g})$ during roasting.

\section{Conclusion}

In conclusion, a QuEChERs method linked with UPLC-MS/MS and GC-MS was respectively evaluated for determination of 7 COPs and 20 HAs in roast duck, with $7 \alpha-\mathrm{OH}$ and $7 \beta-\mathrm{OH}$ dominating in the former while norharman and harman in the latter. For both COPs and HAs, high accuracy and precision were attained meeting the requirements set by TFDA. Most of COPs and HAs showed a higher matrix effect in duck skin and meat due to co-extraction of some impurities, however, the high recovery implied that their quantitation is acceptable. Of the 3 roasting methods, superheated steam oven and fan oven could effectively minimize the formation of total HAs and COPs in duck meat, respectively.

\section{Conflict of interest}

The authors have no conflicts of interest to declare.

\section{Acknowledgement}

This study was supported by a grant from National Research Institute of Health, Taiwan (NHRI107A1-EMCO-2818181).

\section{Appendix A. Supplementary data}

Supplementary data to this article can be found online at https://doi.org/10.38212/2224-6614.1066.

\section{References}

[1] Chang CC, Kao TH, Zhang D, Wang Z, Inbaraj B, Hsu KY, et al. Application of QuEChERS coupled with HPLC-DAD-
ESI-MS/MS for determination of heterocyclic amines in commercial meat products. Food Anal Methods 2018;11: 3243-56.

[2] Chiu CW, Kao TH, Chen BH. An improved analytical method for determination of cholesterol oxidation products in meat and animal fat by QuEChERS coupled with gas chromatography-mass spectrometry. J Agric Food Chem 2018;66:3561-71.

[3] International Agency for Research on Cancer (IARC). Some naturally occurring substances: food items and constituents, heterocyclic aromatic amines and mycotoxins. IARC Monogr Eval Carcinog Risks Hum 1993;56.

[4] Lee HW, Chien JT, Chen BH. Formation of cholesterol oxidation products in marinated foods during heating. J Agric Food Chem 2006;54:4873-9.

[5] Hsiao H, Chen BH, Kao TH. Analysis of heterocyclic amines in meat by the quick, easy, cheap, effective, rugged and safe method coupled with LC-DAD-MS-MS. J Agric Food Chem 2017;65:9360-8.

[6] Chen BH, Yang DJ. An improved analytical method for determination of heterocyclic amines in chicken legs. Chromatographia 1998;48:223-30.

[7] Alaejos M, Afonso AM. Factors that affect the content of heterocyclic aromatic amines in food. Compr Rev Food Sci Food Saf 2011;10:52-108.

[8] Felton JS, Knize MG, Hatch FT, Tanga MJ, Colvin ME. Heterocyclic amines formation and the impact of structure on their mutagenicity. Cancer Lett 1999;143:127-34.

[9] Nagao M, Fujita K, Wakabayashi K, Sugimura T. Ultimate forms of mutagenic and carcinogenic heterocyclic amines produced by pyrolysis. Biochem Biophys Res Commun 1983; 114:626-31.

[10] Gibis M, Kruwinnus M, Weiss J. Impact of different panfrying conditions on the formation of heterocyclic aromatic amines and sensory quality in fried bacon. Food Chem 2015; 168:383-9.

[11] Balogh Z, Gray JY, Gomaa EA, Booren AM. Formation and inhibition of heterocyclic aromatic amines in fried ground beef patties. Food Chem Toxicol 2000;38:395-401.

[12] Wong D, Cheng KW, Wang M. Inhibition of heterocyclic amine formation by water-soluble vitamins in Maillard reaction model systems and beef patties. Food Chem 2012;133: $760-6$.

[13] Oz F, Cakmak IH. The effects of conjugated linoleic acid usage in meatball production on the formation of heterocyclic aromatic amines. LWT Food Sci Technol 2016;65:1031-7.

[14] Derewiaka D, Molinska E. Cholesterol transformation during heat treatment. Food Chem 2015;171:233-40.

[15] Khan MI, Min JS, Lee SO, Yim DG, Seol KH, Lee M, et al. Cooking, storage, and reheating effect on the formation of cholesterol oxidation products in processed meat products. Lipids Health Dis 2015;14:89.

[16] Dominguez R, Borrajo P, Rodriguez JML. The effect of cooking methods on nutritional value of foal meat. J Food Compos Anal 2015;43:61-7.

[17] Osada K, Hoshina S, Nakamura S, Sugano M. Cholesterol oxidation in meat products and its regulation by 
supplementation of sodium nitrite and apple polyphenol before processing. J Agric Food Chem 2000:48:3823-9.

[18] Lee HW, Chien JT, Chen BH. Inhibition of cholesterol oxidation in marinated foods as affected by antioxidants during heating. Food Chem 2008;108:234-44.

[19] Tai CY, Chen YC, Chen BH. Analysis, formation and inhibition of cholesterol oxidation products in foods: an overview (Part II). J Food Drug Anal 2000;8:1-15.

[20] Yin J, Chaufour X, McLachlan C, MeGuire M, White G, King N, et al. Apoptosis of vascular smooth muscle cells induced by cholesterol and its oxides in vitro and in vivo. Atherosclerosis 2000;148:365-74.

[21] Soto-Rodriguez I, Campillo-Velazguez PJ, AlexanderAquilera A, Rodriguez-Estrada MT, Lercker G, Garcia HS. Biochemical and histopathological effects of dietary oxidized cholesterol in rats. J Appl Toxicol 2009;29:715-23.

[22] Chang CC, Zhang D, Wang Z, Chen BH. Simultaneous determination of twenty heterocyclic amines in cooking oil using dispersive solid phase extraction (QuEChERS) and high performance liquid chromatography-electrospraytandem mass spectrometry. J Chromatogr A 2019;1585: 82-91.

[23] Statistical Analysis System (SAS). SAS procedures and SAS/ Graph user's guide. Version 6. Gary, NC: SAS Institute Inc.; 2012.

[24] Hsu KY, Chen BH. Analysis and formation of heterocyclic amines and cholesterol oxidation products in chicken by controlling flavorings and roasting condition. Food Res Int 2020;131:109004.

[25] Taiwan Food and Drug Administration (TFDA). Method validation of food analysis. 2013 (In Chinese) Available from: https://www.fda.gov.tw/tc/includes/GetFile.ashx? $\mathrm{id}=\mathrm{f} 636935163435629279 /$ [Last accessed 17.09.20].
[26] Georgiou CA, Constantinou MS, Andreou R, Hapeshi E, Fatta-Kassinos D, Kapnissi-Christodoulou CP. Novel approach to fast determination of cholesterol oxidation products in Cypriot foodstuffs using ultra-performance liquid chromatography-tandem mass spectrometry. Electrophoresis 2015;37:1101-8.

[27] Matuszewski BK, Constanzer ML, Chavez-Eng CM. Strategies for the assessment of matrix effect in quantitative bioanalytical methods based on HPLC-MS/MS. Anal Chem 2003;75:3019-30.

[28] United States Department of Agriculture (USDA). Food and nutrient database for dietary studies (FNDDS), FoodData central. National Agricultural Library; 2019. Available from: https://fdc.nal.usda.gov/ [Last accessed 19.06.30].

[29] Chen Y, Chien J, Inbaraj BS, Chen BH. Formation and inhibition of cholesterol oxidation products during marinating of pig feet. J Agric Food Chem 2011;60:173-9.

[30] Hur SJ, Park GB, Joo ST. Formation of cholesterol oxidation products (COPs) in animal products. Food Contr 2007;18: 939-47.

[31] Chen LJ, Lu YF, Chen JT, Chen BH. Formation and inhibition of cholesterol oxidation products in tea-leaf eggs during marinating. J Agric Food Chem 2010;58:10467-74.

[32] Skog H, Solyakov A, Jagerstad M. Effects of heating conditions and additives on the formation of heterocyclic amines with reference to amino-carbolines in a meat juice model system. Food Chem 2000;68:299-308.

[33] Borgen E, Solyakov A, Skog K. Effects of precursor composition and water on the formation of heterocyclic amines in meat model system. Food Chem 2001;74:11-9.

[34] Liao GZ, Wang GY, Xu XL, Zhou GH. Effect of cooking methods on the formation of heterocyclic aromatic amines in chicken and duck breast. Meat Sci 2010;85:149-54. 